\title{
Parlamentares no presidencialismo de coalizão: poder decisório na formulação de benefícios tributários
}

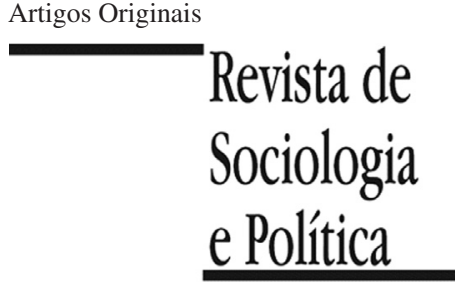

DOI 10.1590/1678-987320287402

\author{
Davi Cordeiro Moreira' \\ IEscola de Relações Internacionais, FGV-SP, São Paulo, SP, Brasil
}

RESUMO Introdução: Analisamos os padrões de atuação dos parlamentares brasileiros responsáveis pela concessão de benefícios tributários referentes ao Programa de integração Social (PIS), à Contribuição para o Financiamento da Seguridade Social (COFINS) e à Contribuição Social sobre Lucro Líquido (CSLL) durante os governos de Fernando Henrique Cardoso (1995-2002) e de Luiz Inácio Lula da Silva (2003-2010). Considerando que sua implementação desperta fortes incentivos pessoais aos políticos, uma vez que interessa a setores econômicos que almejam redução de carga tributária, nos perguntamos: dada a divisão de poderes que caracteriza o presidencialismo de coalizão brasileiro, onde reside o poder decisório na formulação dessa política pública? Materiais e métodos: Os dispositivos legais que concedem e delimitam o acesso aos benefícios tributários referentes ao PIS, à COFINS e à CSLL foram adotados como principal unidade de análise do conteúdo legislativo. Sua contabilização foi utilizada para identificar onde foi produzido o conteúdo legal posteriormente aprovado. Resultados: A formulação da política de concessão de benefícios tributários referentes ao PIS, à COFINS e à CSLL está submetida à agenda da coalizão governista, que anula anseios individuais dos parlamentares através do uso estratégico das regras do processo decisório. Além disso, a supressão da influência individual dos parlamentares não anula sua participação na formulação dessa política pública. Através das lideranças partidárias, o Legislativo atua de forma propositiva sobre seu conteúdo e, não raramente, supera o poder Executivo em sua criação. Discussão: Há duas principais contribuições à literatura sobre o tema. Primeiro, a análise da formulação da política pública traz à luz a participação propositiva e assídua do Poder Legislativo no conteúdo aprovado. É justamente na janela de oportunidade aberta pela dominância legislativa do poder Executivo federal que os parlamentares brasileiros têm a oportunidade de colaborar na elaboração do conteúdo das políticas públicas. Segundo, as conclusões empíricas deixam de lado a hipótese de que a formulação da política de benefícios tributários seja um alicerce do possível quid pro quo existente entre políticos e grupos de interesse. Se a análise pode apontar para um padrão de como se concretiza a relação entre Estado e grupos de interesse no Brasil, ao invés de ser individualmente concretizada, a pesquisa indica que essa relação é construída partidariamente. Logo, se há algum tipo de conexão eleitoral ou de quid pro quo, nossa aposta é de que esta deve ser pensada em termos partidários e não estritamente pessoais.

PALAVRAS-CHAVE: estudos legislativos; benefícios tributários; políticas públicas; relações Executivo-Legislativo; análise de conteúdo.

Recebido em 22 de Dezembro de 2018. Aprovado em 15 de Outubro de 2019. Aceito em 18 de Abril de 2020.

\section{Introdução ${ }^{1}$}

\footnotetext{
${ }^{1}$ Agradeço ao Prof. Dr. Wagner Mancuso pelo incentivo acadêmico que motivaram minha dedicação a esta temática, ao Prof. Dr. Paolo Ricci pela supervisão e à equipe de pesquisadores do Grupo de Estudos Legislativos do CEBRAP - Andreia Freitas, Jaqueline Zulini, Danilo Medeiros, Rafael Freitas e Samuel Moura -, cujo auxílio foi essencial para a construção do banco de dados original. Agradeço aos comentários e sugestões dos pareceristas
}

667 erhaps the most common way to keep the costs of a program relatively invisible is to use the tax code rather than the budget for delivering benefits. Most changes in the tax code are written in technical language and are relatively obscure to all except those who will use them, whereas all direct subsidies are listed prominently in the federal budget. Perhaps that is why tax deductions and tax credits have been the favorite devices for delivering benefits to corporations and wealthy groups in society" (Arnold, 1990, p.113).

A Constituição Federal de 1988 deu ao Poder Executivo Federal amplos poderes legislativos. Entre eles, destaca-se o poder de agenda e a possibilidade de pautar o trabalho parlamentar (Figueiredo \& Limongi, 1999). Diante de um recorte dedicado à política de benefícios tributários, sem desconsiderar que esta política interessa a setores econômicos que almejam a redução da carga tribu- 
anônimos da Revista de Sociologia e Política. tária e que pode ser utilizada para superar os desafios do país, este artigo responde à seguinte questão: em meio ao arcabouço institucional do Presidencialismo de Coalizão Brasileiro, onde reside o poder decisório na formulação desta política pública?

O objetivo principal deste artigo é averiguar com detalhes ao longo dos governos de Fernando Henrique Cardoso (1995-2002) e de Luiz Inácio Lula da Silva (2003-2010) como se comportaram os atores envolvidos no processo de formulação da política de benefícios tributários. Para tanto, analisamos minuciosamente a formulação de todos os benefícios concedidos em relação a três tributos: a Contribuição para o Programa de Integração Social (PIS), a Contribuição para o Financiamento da Seguridade Social (COFINS) e a Contribuição Sobre o Lucro Líquido (CSLL).

A literatura que analisa a alocação de recursos públicos federais por meio da atividade legislativa tem se dedicado ao estudo dos gastos diretos do governo a partir, basicamente, da análise do processo orçamentário federal com o objetivo de verificar a relação entre os Poderes Executivo e Legislativo e a capacidade dos atores envolvidos influenciarem sua alocação (Ames, 1995a; 1995b; 2002; Figueiredo \& Limongi, 2002; 1999; 2010; Limongi \& Figueiredo, 1998, 2005; Mainwaring, 1991; 1999; Pereira \& Mueller, 2002). Sua análise confronta dois modelos teóricos presentes nos estudos legislativos, o modelo distributivista e o modelo partidário. No primeiro caso, busca-se a comprovação ou anulação de uma provável conexão eleitoral entre parlamentares e eleitores. No segundo, busca-se a comprovação ou anulação da tese de que no Presidencialismo de Coalizão Brasileiro (Abranches, 1988) existe uma constante e impiedosa disputa entre os poderes Executivo e Legislativo no que tange a formulação de políticas públicas.

Avançando nesse debate, análises sobre o conteúdo legislativo proposto ou aprovado apontam que no caso brasileiro não há uma dicotomia entre os dois modelos teóricos (Lemos, 2001; Lemos \& Ricci, 2011; Pereira \& Mueller, 2003; Ricci, 2003b; 2006). As conclusões indicam que a preponderância do modelo partidário não anula práticas distributivistas.

Visando contribuir com a ampliação desta literatura, consideramos conveniente analisar outro tipo de gasto, o gasto indireto do governo federal, que é realizado através da política de benefícios tributários. Para que se tenha uma breve descrição da importância desta política pública, em 2010 a política de benefícios tributários referente às contribuições selecionadas tinha como estimativa renunciar 49 bilhões de reais, valor equivalente a $73 \%$ do orçamento aprovado para o Ministério da Saúde no mesmo ano (R \$ 66,9 bilhões).

Sem qualquer intuito de defender ou atacar a concessão de benefícios tributários enquanto opção política para os desafios do país, verificamos em que medida o Poder Legislativo participa de sua formulação. Nosso objetivo não é comprovar ou refutar a existência de vínculos entre autoridades representativas e grupos de interesse, pois consideramos que este tipo de relação compõe a natureza de regimes democráticos modernos definidos enquanto governos representativos (Manin, 1997; Przeworski, Stokes \& Manin, 1999). Analisamos o processo decisório da política em questão e verificamos como se deu a oferta de benefícios tributários diante das regras do processo legislativo brasileiro.

Em acordo com a abordagem conferida por Figueiredo e Limongi (2002, 2005) a conclusão central deste artigo é a de que a formulação desta política está submetida à agenda da coalizão governista e, devido ao padrão de concentração de poderes no interior do processo legislativo, não é possível atribuir sua formulação a anseios individuais dos parlamentares e muito menos a uma disputa intrínseca entre os Poderes Executivo e Legislativo. Ademais, este 
artigo avança no que diz respeito à compreensão dos fatores que sustentam a coalizão governista, indicando que esta é também construída com base na participação propositiva do Legislativo Federal sobre os projetos de lei que são por ele analisados.

$\mathrm{Na}$ segunda seção apresentamos a fundamentação teórica do artigo. $\mathrm{Na}$ terceira, fundamentamos conceitualmente os benefícios tributários referentes às contribuições sociais no Brasil e expomos um breve histórico da implementação desta política. Dedicamos a quarta seção aos aspectos metodológicos da pesquisa, exploramos a natureza de nosso objeto e, através de critérios qualitativos, definimos com precisão nossa unidade de análise. A quinta seção é dedicada à análise empírica dos dados. Por fim, apresentamos breves considerações.

\section{Comportamento político e Conteúdo legislativo}

A literatura que busca explicar a concessão de benefícios por parte dos representantes políticos em regimes democráticos deriva dos modelos teóricos que embasam os estudos legislativos: o modelo distributivista (Cain, Ferejohn \& Fiorina, 1990; Downs, 1957; Fiorina, 1989; Mayhew, 1974), o modelo informacional (Krehbiel, 1992) e o modelo partidário (Cox \& Mccubbins, 2007; Mccombs, 2004). Para os fins deste trabalho, podemos dividir esta literatura em duas vertentes: uma que explica a concessão de benefícios com base nos incentivos gerados pela arena eleitoral e outra cujo escopo analítico se debruça sobre as regras que regem os processos decisórios.

Mais do que hierarquizar as diferentes abordagens explicativas referentes ao comportamento político, vamos elencá-las de modo que se tenha conhecimento da amplitude de variáveis que podem explicar a tomada de decisões políticas em democracias modernas. A seguir abordamos essas duas vertentes e apresentamos como este debate se desenvolveu no caso brasileiro.

\section{II.1. Incentivos Eleitorais, Comportamento Político e Conteúdo Legislativo}

Somado à tese do voto pessoal, no modelo distributivista as regras eleitorais determinariam o comportamento legislativo do representante (Cain, Ferejohn \& Fiorina, 1990; Downs, 1957; Fiorina, 1989; Mayhew, 1974). Diante de regras eleitorais que favorecessem a relação direta entre político e eleitor, políticos sensatos não perderiam a oportunidade de maximizar a distribuição de benefícios particulares a seus redutos eleitorais com o objetivo de obter os créditos por concessões realizadas (credit claiming) (Mayhew, 1974) e aumentar as chances de sua manutenção no poder.

Pela lógica desta literatura, quanto mais incentivos pessoais o sistema eleitoral proporcionar, mais os políticos canalizam, de forma individual, benefícios a seu eleitorado. Contudo, o modelo distributivista não se restringe à relação direta entre políticos e eleitores. Sua abordagem permite a inclusão de outros atores presentes na relação representante-representado como, por exemplo, a atuação de grupos de interesse. Três seriam as principais razões para a inserção de grupos de interesse nas análises que buscam explicar o comportamento político dos representantes: sua capacidade de organização, a assimetria de informação presente na sociedade como um todo e o financiamento de campanhas.

Do ponto de vista da organização dos grupos, em A Lógica da Ação Coletiva (1971), Mancur Olson destaca que qualquer ação coletiva incorre no problema do carona (free-rider problem) $)^{2}$. Por isso, grupos de interesse, em menor número de membros, têm maior capacidade de organização para pressio-

${ }^{2}$ Problema que consiste na hipótese de indivíduos não 
assumirem os custos de uma determinada ação e aguardarem pelos benefícios de um empreendimento através dos custos assumidos por outros (Olson, 1971). nar os representantes em processos decisórios. Olson, por exemplo, destaca que as distorções encontradas no sistema tributário norte-americano estão diretamente relacionadas à ação de grupos de interesse que buscam reduzir o peso dos impostos sobre as atividades econômicas que desenvolvem. Políticos pressionados por grupos bem organizados tenderiam a beneficiá-los com o objetivo de aumentarem sua competitividade em eleições futuras.

Sem desconsiderar a tese desenvolvida por Olson, Susanne Lohmann argumenta que o “Olson's free-rider problem is not (...) a sufficient explanation for inefficient redistribution favoring a minority. After all, if the majority of voters understood that they are paying the bill for special interest handouts, they would surely punish their political leaders by voting them out of office. For Olson's logic to work, it seems voters must be stupid or ill informed" (2003, p.303). Para a autora, não é apenas a maior capacidade de organização que possibilita aos grupos de interesse ganhos políticos em relação à população em geral, o que favorece a atuação política de representantes em favor de grupos de interesse é o impacto político da assimetria de informação existente entre pequenos grupos e a população como um todo.

Como Downs (1957) apresenta, a lógica de funcionamento das democracias representativas impõe limites à ampla informação. Cada eleitor pode ser considerado um interesse organizado em algumas áreas. No entanto, em relação à grande maioria dos temas sobre os quais a atividade política se debruça, o eleitorado tem apenas uma vaga ideia do impacto gerado pelas decisões que são constantemente tomadas. Somente em relação às dimensões sociais nas quais o eleitor é especializado que é possível a ele auferir o que os políticos têm feito contra ou a seu favor (Downs, 1957; Lohmann, 2003).

Outra variável que advém da arena eleitoral não é necessariamente o voto proporcionado pelos benefícios concedidos a grupos organizados e bem informados sobre a atividade política, mas sim os recursos que grupos beneficiados podem ofertar para promover candidatos de seu interesse. Do ponto de vista do candidato que pretende perpetuar sua carreira política, é racional o estabelecimento de vínculos com grupos que já financiaram sua campanha ou apresentam potencial para tal. Se do ponto de vista do candidato há incentivos para a procura por recursos, do ponto de vista dos grupos de interesse uma série de estudos buscam provar empiricamente a influência do financiamento de campanha sobre a ação dos políticos e os resultados das políticas públicas (Baron, 1994; Potters \& Sloof, 1996; Smith, 1995).

Vemos portanto que a vertente que analisa a concessão de benefícios com base no modelo distributivista e no modelo informacional dedica à arena eleitoral a concessão de benefícios por parte da atividade individual do representante político. Sendo assim, o que podemos dizer sobre a submissão dos representantes eleitos às regras que regem os processos decisórios?

\section{II.2. Arena Legislativa, Comportamento Político e Conteúdo Legislativo}

Como uma crítica à literatura vista até agora, estudos passaram a apresentar que independente dos incentivos gerados pelo sistema eleitoral e da pressão realizada por grupos de interesse, a atividade legislativa se submete também às regras procedimentais das instituições que regulam o processo decisório. Deste modo, o particularismo legislativo se daria, na verdade, em função dos procedimentos adotados e da análise estratégica que os representantes políticos fazem dos contextos nos quais estão inseridos.

Regras procedimentais, tais como a exclusividade de iniciativa legislativa, mecanismos de urgência que limitam o debate em plenário, a escolha do tipo de votação final sobre a matéria e etc., concentram as decisões em postos-chave do 
${ }^{3}$ Veremos na Seção 5, Análise Empírica, que podemos considerar este fato para o caso brasileiro durante $\mathrm{O}$ governo FHC.

\section{II.3. O caso brasileiro}

processo legislativo, tendem a reduzir interesses particularistas dos representantes e fortalecem as lideranças partidárias (Cox, 2005). Se isto é verdade, convém perguntar se tais regras não modificariam o conteúdo legislativo aprovado uma vez que há a possibilidade de controlar anseios individualistas estimulados pelas regras eleitorais (Shepsle \& Weingast, 1984, p.71).

Para esta literatura, a resposta é sim (Döring, 2001; Ricci, 2006). A concentração dos poderes não só permite um controle maior sobre a produção legislativa (Döring, 2001), como "procedural strategies are used to manipulate the circumstances under which legislator are forced to take public positions" (Arnold, 1990, p.99). Logo, estamos diante do modelo partidário (Cox \& Mccubbins, 2007; Mccombs, 2004), cujo argumento principal sustenta que as regras do processo legislativo podem permitir o controle das lideranças partidárias sobre suas bases. Mais do que refutar a participação parlamentar ou submetê-la a seus anseios, significa dizer que o governo pode ter em suas mãos mecanismos de negociação que permitem definir em que medida deputados e senadores estão livres para interferir na produção legislativa.

Um processo decisório desse tipo tem, portanto, forte impacto sobre o conteúdo legislativo que será aprovado. Diversos estudos demonstram como o controle sobre o processo decisório orçamentário permite garantir decisões mais eficientes em termos de disciplina fiscal ${ }^{3}$ (Alesina et al., 1999; Hallerberg \& Von Hagen, 1997; Von Hagen, Hallett \& Strauch, 2001), sendo possível reduzir o número de projetos de lei de baixa relevância, em particular aqueles que seriam utilizados para a concessão de benefícios territorialmente localizados.

Em resumo, podemos identificar que todas as variáveis apresentadas para explicar o comportamento político dos representantes eleitos em favor de grupos de interesse se comportam de forma complementar. Com base nas regras que regem o processo legislativo brasileiro, este trabalho se dedica a verificar se é por meio da atuação individual dos representantes do país que são formulados benefícios tributários a setores e atividades econômicas.

No caso brasileiro, a análise da alocação de recursos públicos através do processo legislativo tem se dedicado, principalmente, ao estudo do processo orçamentário nacional com o objetivo de debater a governabilidade proporcionada pelas instituições de âmbito federal.

Encontramos nessa literatura ao menos duas vertentes diferentes, uma baseada no modelo distributivista e outra no modelo partidário. A primeira se dedica aos aspectos institucionais da relação Executivo-Legislativo e ao comportamento político sob a ótica da tese do voto pessoal (Ames, 1995a; 2002; Mainwaring, 1991; 1999; Pereira \& Mueller, 2002). A segunda, por sua vez, indica que as regras do processo decisório impedem o particularismo legislativo na alocação de recursos públicos federais (Figueiredo \& Limongi, 2002; 2010; Limongi \& Figueiredo, 1998, 2005).

Para a primeira vertente, a produção legislativa brasileira está submetida a um jogo de barganha entre os Poderes Executivo e Legislativo (Pereira \& Mueller, 2002). Em virtude da separação de poderes, própria do presidencialismo, o Executivo Federal não teria como governar, pois a arena parlamentar funcionaria como um poder de veto a suas propostas (Ames, 2002). Para obter governabilidade, em algum momento o Executivo deveria atender a demandas políticas dos parlamentares brasileiros. Um desses momentos de barganha seria o processo orçamentário, principalmente no que tange à execução das emendas individuais. Através dele, o Executivo poderia atender aos anseios de deputados 
e senadores e conferir a eles a decisão sobre a alocação de parte dos recursos da União em troca de apoio político em futuras votações (Pereira \& Mueller, 2002).

Em síntese, essa vertente argumenta que pela execução de emendas individuais aprovadas no processo orçamentário o Poder Executivo conseguiria o apoio necessário à construção de uma ampla coalizão governista no Legislativo. Assim, comportando-se a favor do Executivo, o parlamentar poderia almejar a data em que os recursos de sua emenda seriam liberados e posteriormente colher os frutos políticos oriundos dela. Por outro lado, caso deputados e senadores criassem obstruções à agenda governamental, o Executivo teria amplos poderes para punir os parlamentares ao não autorizar a execução de suas emendas aprovadas.

Contrapondo essa primeira vertente, a segunda abordagem referente à alocação de recursos públicos via processo orçamentário critica o pressuposto de que no presidencialismo de coalizão brasileiro haja um enfrentamento direto entre os Poderes Executivo e Legislativo (Figueiredo \& Limongi, 2002; 2010; Limongi \& Figueiredo, 1998; 2005). Seu argumento fundamental é de que não há diretamente um jogo de barganha entre os Poderes, pois se o Poder Executivo é formado com o objetivo de se obter a maioria no Legislativo, não há porque dizer que exista uma disputa política entre eles. Há, na verdade, uma disputa política entre situação e oposição (Figueiredo \& Limongi, 2002; 2010; Limongi \& Figueiredo, 1998; 2005). Expoentes dessa vertente, Figueiredo e Limongi (2002) afirmam que tratar outputs políticos do país como fruto dos conflitos existentes entre os Poderes Executivo e Legislativo exclui a principal variável dessa relação, os partidos políticos.

No que tange ao processo orçamentário, esses autores $(2002 ; 2005)$ destacam que o processo decisório é centralizado e a concentração de poderes legislativos na Presidência da República induz o parlamentar individual a atuar por meio dos partidos políticos para, de algum modo, obter sucesso em suas ações (2002).

Figueiredo e Limongi (2005) apresentam ao menos três pontos fundamentais referentes a esse processo decisório. Primeiro, mostram que os parlamentares não conseguem interferir individualmente no processo decisório, ficando as decisões-chave submetidas aos trabalhos dos relatores. Apontam que "cabe ao relator geral definir a parcela a ser reivindicada pelo Congresso Nacional para acomodar suas emendas" e "preservar a distribuição original de recursos contida na proposta enviada pelo Executivo" (2002, p.320-321). De modo que a centralização do processo decisório garante aos partidos da base aliada o controle sobre a alocação de recursos dos investimentos da União.

Em segundo lugar, quando são isoladamente analisadas, não é possível estabelecer vínculo direto entre a aprovação das emendas individuais, sua execução e o apoio dos parlamentares ao Executivo. O Executivo privilegia os parlamentares que compõem sua base de governo e, consequentemente, apresentam altos índices de apoio em votações nominais, ou seja, "a execução das emendas individuais é ditada por critérios político-partidários" (Limongi \& Figueiredo, 2005, pp.746-749).

Por fim, testam a hipótese "de que a lógica partidária determina tanto o comportamento em plenário quanto a execução de emendas" (Limongi \& Figueiredo, 2005, pp.752-753) e concluem que a filiação partidária serve como variável explicativa para os dois casos, enquanto o comportamento em plenário não explica a execução de emendas. Assim, consideram que o argumento de que o Poder Executivo enfrenta no Congresso Nacional um ponto de veto perde de vista o principal aspecto do presidencialismo de coalizão brasileiro: de que o 
conflito do sistema político brasileiro não está nas relações entre os Poderes, "mas sim nas clivagens político-partidárias", ou melhor, entre partidos da situação e partidos da oposição (Limongi \& Figueiredo, 2005, p.766).

Pelo que já expomos, se torna possível perguntar se a formulação da política de benefícios tributários é resultado direto da atuação individual dos representantes brasileiros e como se deu a participação dos atores responsáveis pela formulação da política ao longo do tempo. Mas antes de dar este passo, se faz necessário conceituar nosso objeto de pesquisa e apresentar um breve histórico da política de benefícios tributários no Brasil.

\section{A Política de Benefícios Tributários no Brasil}

${ }^{4}$ Art. $3^{\circ}$. Tributo é toda prestação pecuniária compulsória, em moeda ou cujo valor nela se possa exprimir, que não constitua sanção de ato ilícito, instituída em lei e cobrada mediante atividade administrativa plenamente vinculada (Lei 5.172 , de 25 de outubro de 1966).
As contribuições sociais brasileiras são uma exclusividade, não havendo nada semelhante na maior parte dos países (Araújo, 2005). Este fato cria uma enorme discussão referente à sua natureza jurídica, principalmente quando comparadas a taxas e impostos. No entanto, neste artigo adotamos a perspectiva de Sergio Pinto Martins (2009) e consideramos as contribuições sociais espécies do gênero tributo, pois se tratam de prestações pecuniárias compulsórias instituídas em acordo com o artigo $3^{\circ}$ do Código Tributário Nacional ${ }^{4}$.

As três contribuições analisadas por esta pesquisa têm os seguintes fins específicos:

O PIS, criado pela Lei Complementar 7, de 7 de setembro de 1970, com o objetivo de integrar o trabalhador à empresa de forma que este participasse de seu desenvolvimento, financia o seguro-desemprego e o abono de um salário mínimo aos empregados que recebem até dois salários mínimos de remuneração mensal (art. 239 da CF/88). Além disso, pelo menos $40 \%$ de sua arrecadação são destinados ao financiamento de programas de desenvolvimento econômico administrados pelo Banco Nacional de Desenvolvimento Econômico e Social (BNDES).

A COFINS foi criada em 30 de dezembro de 1991 pela Lei Complementar 70 em substituição à cobrança do Finsocial (Decreto Lei 1.940/1982), de modo a regular a participação do empregador no financiamento da seguridade social (art. 195 da CF/88, inciso I).

Por sua vez, a CSLL foi instituída pela Lei 7.689, de 15 de dezembro de 1988, também com objetivo de regular o inciso I do artigo 195 da nova Constituição Federal. O objetivo destas duas contribuições é o financiamento da seguridade social entendida enquanto os direitos relativos à saúde, à previdência e à assistência social.

As finalidades das contribuições apresentadas estão diretamente ligadas ao Orçamento da Seguridade Social que a Constituição de 1988 criou com o objetivo de financiar o bem-estar da população brasileira. Por tal razão, a arrecadação das contribuições sociais é de exclusividade da União, diferenciando-se de outros tributos que são obrigatoriamente distribuídos entre as demais unidades federadas.

Com essas características, podemos então definir que a política de benefícios tributários referentes ao PIS, à COFINS e à CSLL implica claramente na criação de benefícios concentrados e custos difusos no curto prazo (Wilson, 1995).

Sob a vigência da nova Constituição, a arrecadação tributária da União aumentou de forma significativa. Segundo dados do Ministério da Fazenda, a arrecadação total das receitas administradas pela União era de 19,4\% do PIB em 1990 , o equivalente a $\mathrm{R} \$ 55,2$ bilhões, e passou a $23,4 \%$ do PIB em 2009, 
chegando à marca de $\mathrm{R} \$ 698,3$ bilhões naquele ano. Neste mesmo período, a arrecadação das contribuições sociais selecionadas por esta pesquisa (PIS, COFINS e CSLL) passou de 3,2\% do PIB em 1990 (R \$15 bilhões) para 6,1\% em 2009 (R \$193,9 bilhões) (Figura 1).

Araújo (2005) apresenta que pelo menos até o ano de 2004 as contribuições sociais, como um todo, tiveram participação importante no aumento da carga tributária federal. Duas seriam as principais razões. A primeira é que o enfrentamento da crise econômica da década de 1980 exigia um maior recolhimento de recursos por parte da União, que, como estratégia e justificativa para o aumento da carga tributária, valeu-se do aumento das contribuições sociais (Araújo, 2005). A segunda razão está no fato de a União não ser constitucionalmente obrigada a repassar os recursos recolhidos pelas contribuições sociais a Estados e Municípios, garantindo, assim, o domínio completo sobre o volume que foi arrecadado (Araújo, 2005).

Além disso, a vinculação dos recursos a atividades com finalidade pública e social, que poderia ser um entrave para o uso discricionário dos valores arrecadados passou, a partir de 1993, por um processo de desvinculação com a criação do Fundo Social de Emergência (Emenda de Revisão 01/94). A principal finalidade do fundo era tornar obrigatória a desvinculação de $20 \%$ da arrecadação de todos os impostos e contribuições federais até o final de 1995. Entretanto, este artifício foi sucessivas vezes prorrogado. Posteriormente, este fundo seria representado pelo Fundo de Estabilização Fiscal (EC 10/1996 e 17/1997) e atualmente a desvinculação de recursos se dá por meio da Desvinculação de Recursos da União (DRU), cuja vigência foi prorrogada até 2023 (EC 27/2000, 42/2003, 56/2007, 68/2011 e 93/2016). Convém destacar que a EC 93 de 8 de setembro de 2016 não só prorrogou a DRU até 2023 como ampliou o percentual de desvinculação para $30 \%$ de todos os impostos e contribuições sociais federais.

A maior crítica que se fez em virtude do aumento das contribuições está no fato de elas serem cumulativas, ou seja, ao incidirem sobre produtos em diferentes momentos da cadeia produtiva, acabam por onerar toda a produção e contribuir para a regressividade da carga tributária brasileira ao atingir indiretamente o consumidor final. Assim, queixas referentes à abusiva carga tributária e

Figura 1 - Carga Tributária da União - Total e Contribuições Selecionadas (\% do PIB)

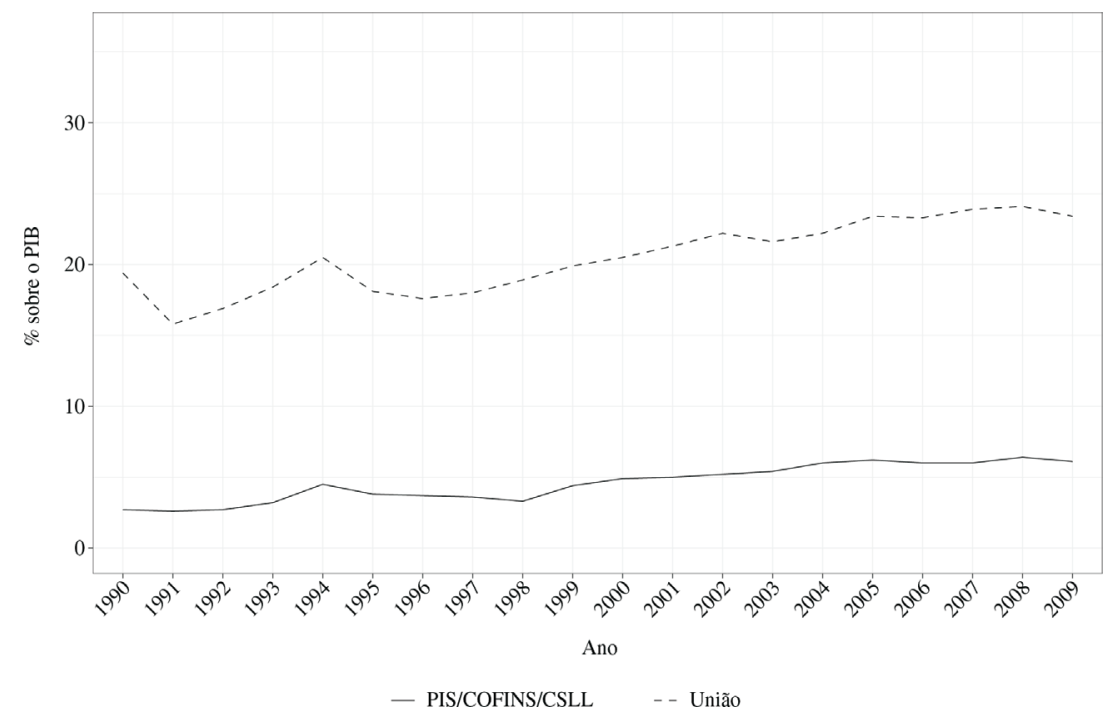

Fonte: Elaboração própria. 
à complexidade do sistema tributário nacional levaram o Executivo Federal a propor sucessivos projetos de reforma tributária nos últimos anos (PEC 175/1995, 41/2003 e 233/2008). Até o momento, nenhum deles obteve sucesso e o tema volta ao topo da agenda do governo que tem início em 2019.

A despeito de fracassos, os governos federais não se restringiram às propostas de reforma e promoveram uma série de mudanças no sistema tributário nacional que estão diretamente vinculadas à arrecadação das contribuições sociais. Entre elas, encontra-se a constante aprovação de benefícios tributários a setores e atividades econômicas do país.

No que se refere às contribuições que serão aqui analisadas, as estimativas de renúncia tributária divulgadas pela Receita Federal ao longo do período destacam o crescente aumento do volume de recursos abdicados pela União. Só para o ano de 2010, a estimativa de renúncia do PIS, da COFINS e da CSLL juntos ultrapassou os 49 bilhões de reais. Ao longo dos anos, vemos também que as renúncias referentes às contribuições selecionadas aumentaram constantemente sua participação no total de renúncias de receitas estimadas da União (Figura 2). Para o ano de 2010, esta participação ultrapassa os $40 \%$, principalmente em virtude das renúncias referentes à COFINS, que, sozinha, representa quase $30 \%$ do total.

O forte crescimento da renúncia das contribuições selecionadas não aparece apenas quando comparadas às renúncias totais da União. Em relação às suas respectivas arrecadações, a estimativa de recursos renunciados também apresenta forte crescimento ao longo dos anos (Figura 3).

Vemos que em relação às suas respectivas arrecadações, as renúncias fiscais do PIS, da COFINS e da CSLL cresceram potencialmente nos últimos anos, atingindo respectivamente a marca de $17 \%, 24 \%$ e $18 \%$ de suas arrecadações em 2010 ou o equivalente à renúncia de $\mathrm{R} \$ 6,9$ bilhões, $\mathrm{R} \$ 33,9$ bilhões e $\mathrm{R} \$ 8,3$ bilhões contra a arrecadação de $\mathrm{R} \$ 40,5$ bilhões, $\mathrm{R} \$ 139,7$ bilhões e $\mathrm{R} \$ 45,9$ bilhões, respectivamente. Com relação a essas informações, não podemos deixar de destacar que os relatórios que publicam as estimativas da renúncia federal apresentam muitos problemas (Maciel, 2010; Mancuso \& Moreira,

Figura 2 - Renúncia de Receita Estimada (PIS, COFINS e CSLL) sobre a Renúncia da União (\%)

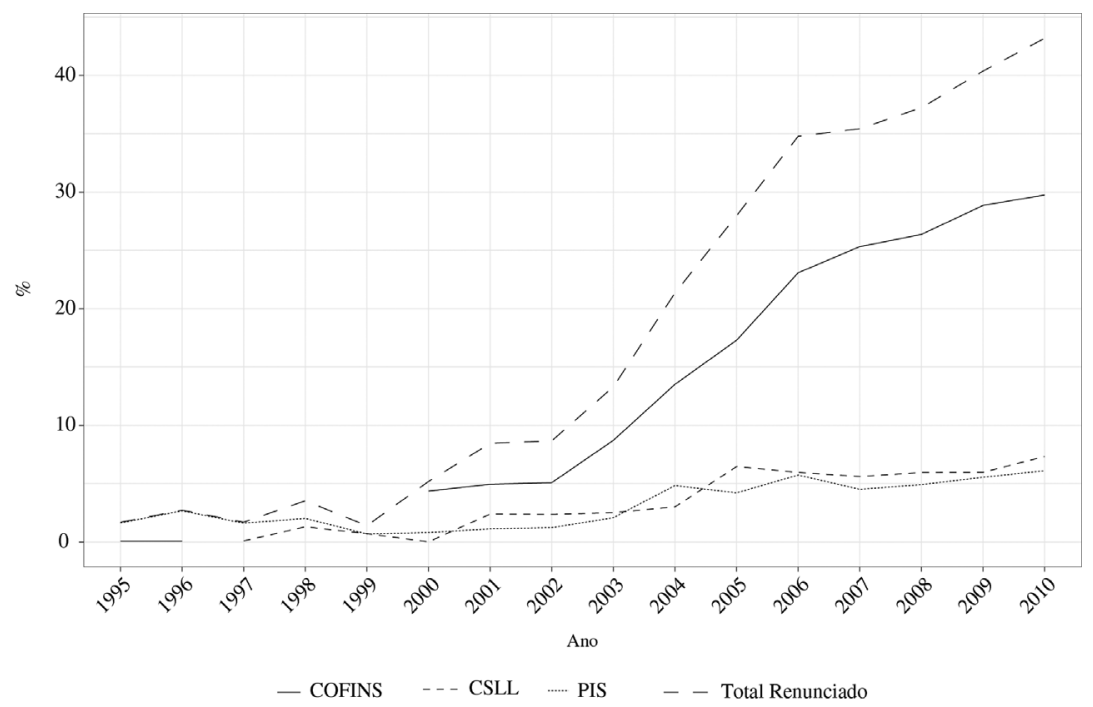

Fonte: Elaboração própria. 
${ }^{5}$ Para mais detalhes, consulte (Moreira, 2011, Anexo 6).

\section{Aspectos Metodológicos}

Figura 3 - Renúncia de Receita Estimada (PIS, COFINS e CSLL) sobre suas respectivas arrecadações (\%)

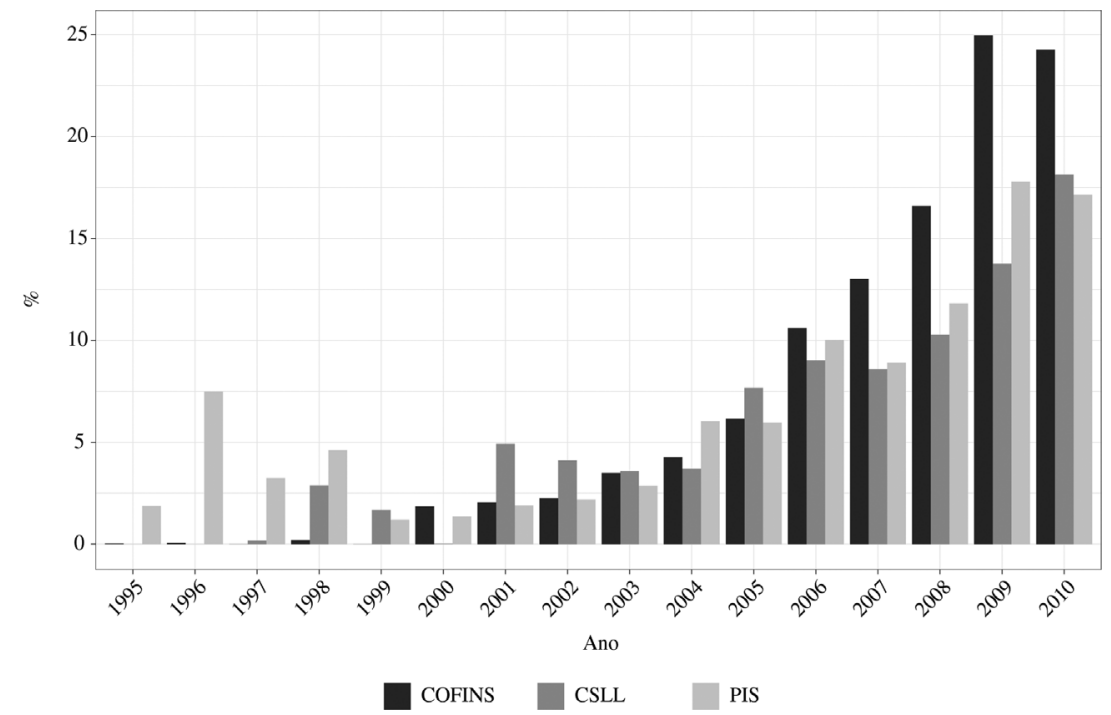

Fonte: Elaboração própria.

2013) e que sofrem de grande defasagem com relação aos valores efetivamente renunciados 5 .

Os dados apresentados nos mostram que o volume renunciado e sua crescente expansão não são desprezíveis. Tais fatores tornam relevante o desenvolvimento de pesquisas que compreendam e busquem esclarecer como os representantes políticos concedem benefícios a setores e atividades econômicas do país.

A escolha do PIS, da COFINS e da CSLL como parte do objeto desta pesquisa se deu por cinco razões. Em primeiro lugar, como já exposto, porque as contribuições sociais são vinculadas e seu recolhimento está atrelado a uma atividade estatal de fim específico direcionado ao interesse geral como o seguro-desemprego e a seguridade social, de modo que qualquer interferência sobre sua arrecadação impacta diretamente sobre o orçamento das atividades às quais estão vinculadas.

Em segundo, como vimos, porque essas três contribuições são responsáveis por grande parcela das renúncias da União, chegando a quase $50 \%$ do total de recursos renunciados em 2010, e ao mesmo tempo representam, em média, 30\% da arrecadação federal total entre 1995 e 2010. É importante ainda ressaltar que diferente de outros tributos como o IPI, por exemplo, a arrecadação das contribuições sociais impacta somente sobre o orçamento do governo federal. Ou seja, ao conceder benefícios tributários referentes a elas, o governo federal está exclusivamente abrindo mão de parte de sua receita.

Em terceiro lugar, porque a Constituição Federal de 1988 prevê que a aprovação de benefícios fiscais referentes a elas deve se dar através do processo legislativo federal, o que possibilita, portanto, analisar o comportamento do Poder Executivo e Legislativo a seu respeito. Esta é a principal razão pela qual consideramos viável a análise da formulação da política de benefícios tributários para compreender, de forma específica, o poder individual do parlamentar 
sobre o conteúdo aprovado e, de forma geral, o poder decisório do legislativo nacional na formulação da política pública.

Em quarto, porque essas três contribuições percorrem sem interrupção quatro mandatos presidenciais consecutivos e completos - diferente, por exemplo, da Contribuição Provisória sobre a Movimentação ou Transmissão de Valores e de Créditos e Direitos de Natureza Financeira (CPMF) que deixou de existir no segundo governo Lula ao não ser prorrogada no ano de 2007.

Em quinto lugar, pelo fato de haver pesquisas sobre as renúncias desses tributos, como é o caso do artigo de Mancuso et al. (2010) e por esse ser um tema pouco explorado pela ciência política brasileira.

Como as políticas de benefícios tributários referentes ao PIS, à COFINS e à CSLL são fruto do processo legislativo, é através da análise do conteúdo presente no texto de medidas provisórias editadas e leis aprovadas que é possível encontrar quais são os representantes brasileiros responsáveis por sua formulação e onde reside o poder decisório a seu respeito. A escolha de critérios adequados para a definição do conteúdo das leis que serão analisadas é de vital importância para qualquer trabalho que se proponha a esse desafio (Ricci, 2010, p.19).

IV.1. Definição das Unidades de Análise

${ }^{6}$ A revisão e atualização do quadro de leis que concedem benefícios tributários referentes ao PIS, à COFINS e à CSLL foram feitas com base nas informações disponíveis na página da Presidência da República (http://www4.planalto.gov.br/l egislacao/) e na página da Câmara dos Deputados (http://camara.leg.br/) com apoio da Coletânea da Legislação PIS/PASEP e COFINS disponível na página da Secretaria da Receita Federal do Brasil (SRF) (http://www.receita.fazenda.go v.br/). Acessado em 15 de abril de 2020

${ }^{7}$ Agradeço ao Prof. Dr. Wagner Pralon Mancuso o envio de seu relatório de pesquisa, Lobby e Renúncia Tributária da União:
Há tempos a ciência política mobiliza esforços para interpretar o conteúdo das leis. Mais recentemente, com a ascensão das análises sobre a produção legislativa, a variável conteúdo tem sido adotada para a formulação de hipóteses e a compreensão das relações contidas nos processos de tomada de decisão (Ricci, 2010).

Ricci (2003a, 2010) nos apresenta como a ciência política americana e a italiana desenvolveram classificações diferentes para o conteúdo das leis. Ambas as escolas estariam por ele inseridas numa vertente analítica denominada Disagregation Approach, cuja abordagem está na classificação do conteúdo das leis em função de seus efeitos programados ou efetivos sobre a sociedade (Ricci, 2010). Ainda segundo Ricci (2010), esta vertente se diferencia da que denomina Importance Approach, cuja abordagem classifica as leis de acordo com uma interpretação sobre seu nível de importância. Este trabalho está associado à primeira vertente e se debruça sobre a revisão e atualização ${ }^{6} \mathrm{da}$ seleção de leis feita por Mancuso e Moreira (2013, Quadro 1)7.

Diferente dos trabalhos existentes, mesmo considerando o processo legislativo enquanto unidade fundamental para estudo do comportamento político, nossa principal unidade de análise não será a lei em sua integralidade, mas sim a desagregação de seu conteúdo. Com o objetivo de "conceber alguns critérios que permitam reconhecer nas leis elementos meramente distributivos" (Ricci, 2003a, p.706), valemo-nos da abordagem metodológica que Couto e Arantes (2006; 2009) aplicam à análise da vigente Constituição brasileira com base no que denominam "dispositivos legais". Uma vez que a estrutura legal possui uma organização lógica e racional basicamente dividida em tópicos (artigos, incisos e alíneas), estes autores os consideram como unidade de análise desde que transmitam informações que possam ser classificadas por critérios pré-estabelecidos. Segundo suas próprias palavras:

Chamamos de 'dispositivo' a unidade básica que compõe o texto constitucional. Examinamos artigos, parágrafos, incisos e alíneas que formam a Constituição, decompondo-os e algumas vezes agrupando-os até que seja possível circunscrever o elemento constitucional que está sendo veiculado. [...]. A contagem de artigos pode ser traída pelos subitens neles contidos e a de palavras ou linhas compromete a comparação entre constituições, uma vez que a diversidade de 
Contribuições para uma análise da Política de Concessão de Benefícios Tributários ao empresariado industrial no Brasil (1988-2006) (2008) e também do quadro detalhado que disponibiliza ao público na nota 4 , página 220 , do capítulo "Colcha de retalhos: a política de concessão de benefícios tributários ao empresariado no Brasil (1988-2006)", presente no livro Estado, Empresariado e Desenvolvimento no Brasil: Novas Teorias, Novas Trajetórias (Mancuso, Gonçalves \& Mencarini, 2010).

${ }^{8} \mathrm{~A}$ lista de dispositivos selecionados se encontra no banco de dados desta pesquisa, que está disponível no Consórcio de Informações Sociais (CIS) pelo seguinte endereço:

http://www.nadd.prp.usp.br/cis /DetalheBancoDados.aspx?co d=B461, acessado em 17 de abril de 2020. Caso não seja possível obtê-lo dessa maneira, escreva para: davi.moreira@gmail.com. Além do livro de códigos que acompanha o banco de dados, para sua melhor compreensão recomendamos a leitura de Moreira (2011, Anexo 4). ${ }^{9}$ Duas medidas provisórias (MPs) não chegaram a ser apreciadas pelo Poder Legislativo em função da EC 32/2001. Seu texto estabeleceu que as MPs já editadas até a línguas e de culturas jurídicas pode ensejar diferentes estilos literários de redação e textos constitucionais, alguns mais dissertativos e outros mais enxutos (Couto \& Arantes, 2009, p.37, nota 12)

Consideramos que a lógica analítica apresentada é bastante promissora para os propósitos dessa pesquisa e inova sobre a análise do conteúdo legislativo brasileiro. As pesquisas desenvolvidas tradicionalmente analisam as leis em sua integralidade (Mancuso \& Moreira, 2013; Ricci 2003a, 2003b; 2006), deixando de considerar, por exemplo, o fato de que uma única lei pode tratar de diferentes assuntos conforme apontam suas próprias ementas quando enunciam que darão “outras providências". Para que se tenha um exemplo, a Lei Ordinária 12.350 de 2010, ao mesmo tempo em que sua ementa enuncia a regulação de atividades ligadas à Copa do Mundo FIFA de 2014, em seu texto concede benefícios tributários a setores e empresas ligadas à atividade agropecuária.

Sendo os benefícios tributários referentes ao PIS, à COFINS e à CSLL concedidos por qualquer tipo de espécie normativa que tenha força de lei, podemos desagregá-las em dispositivos para identificar com precisão quais artigos, incisos, parágrafos e alíneas contidos em seu interior apresentam de fato o conteúdo responsável por conceder e delimitar os benefícios tributários. Assim, construímos um banco de dados cronológico com base na criação de dispositivos legais que vai de janeiro de 1995 até o final de 2010.

Classificamos cada dispositivo de acordo com a espécie normativa que que lhe conferiu força de lei: medida provisória (MP), lei ordinária (LO) ou projeto de lei complementar (LCP). E também verificamos quais foram os atores responsáveis pela autoria de cada um segundo três categorias (Tabela 1).

A seleção de dispositivos impõe um grande desafio ao pesquisador, uma vez que o trabalho qualitativo envolvido lhe garante imensa discricionariedade. Realizada pelo autor deste artigo, todo o cuidado foi tomado para que não houvesse a seleção de dispositivos que não se enquadrassem nas categorias de benefícios criadas com base na Lei de Responsabilidade Fiscal ou não regulassem diretamente o acesso a eles. Também foi feita a leitura e análise do texto das leis (artigo por artigo, parágrafo por parágrafo, inciso por inciso e alínea por alínea) com o objetivo de não deixar de fora qualquer dispositivo que pudesse ser considerado. Ao dedicar esforços sobre cada dispositivo da lei, captamos o ponto exato em que a informação sobre a concessão de benefícios tributários é emitida $^{8}$.

Para realizar a classificação da Tabela 1, atribuímos todos os dispositivos criados por medidas provisórias e mantidos no texto final da lei ao Poder Executivo ${ }^{9}$. Considerando o momento de apresentação e autoria dos disposi-

Tabela 1 - Classificação da Autoria dos Dispositivos

\begin{tabular}{lll}
\hline Tipo de Autoria & Descrição \\
\hline $1 \quad$ Exclusiva do Poder & $\begin{array}{l}\text { Refere-se a dispositivos originalmente propostos pelo Poder } \\
\text { Executivo }\end{array}$ & $\begin{array}{l}\text { Executivo que chegaram ao final de todo o processo } \\
\text { legislativo sem alteração }\end{array}$ \\
2 Exclusiva do Poder & $\begin{array}{l}\text { Refere-se a dispositivos originalmente propostos pelo Poder } \\
\text { Legislativo que chegaram ao final de todo o processo } \\
\text { legislativo }\end{array}$ \\
& $\begin{array}{l}\text { Refere-se a dispositivos propostos pelo Poder Executivo } \\
\text { que chegaram ao final de todo o processo legislativo após } \\
\text { alguma alteração de conteúdo proposta pelo Poder } \\
\end{array}$ \\
& Legislativo
\end{tabular}

Fonte: Elaboração própria. 
data de sua publicação vigorassem indefinidamente até que o Congresso Nacional deliberasse sobre elas ou que MP ulterior as revogasse. São elas: a MP 2.158-35, de 24 de agosto de 2001, e a MP 2.228-1, de 6 de setembro de 2001

${ }^{10} \mathrm{~A}$ contagem dos dispositivos seguiu o número de contribuições ao qual se referia. Se um dispositivo se referia somente ao PIS, ele foi contado apenas uma vez. Se um dispositivo se referia ao PIS e à COFINS, ele foi contado duas vezes. Se outro dispositivo se referia ao PIS, à COFINS e à CSLL, ele foi contado três vezes. tivos que foram posteriormente sancionados, através da leitura e análise dos projetos foi possível definir a "paternidade" dos dispositivos que não estavam presentes nas medidas provisórias ou nos projetos de lei encaminhados pelo Executivo Federal ao Congresso Nacional, mas compunham o conteúdo das leis.

É importante reforçar que nossa atenção está voltada para os dispositivos que regularam a concessão de benefícios tributários através do processo legislativo. Inovações institucionais podem impedir que alguns benefícios tributários vinculados às contribuições selecionadas sejam captados. Uma inovação institucional conferida pela Lei 11.196/2005, por exemplo, deu ao Poder Executivo total autonomia para regular por decreto, quando bem entender, as alíquotas referentes à COFINS incidentes sobre uma seleção de produtos químicos e farmacêuticos. Como dedicamos nossa análise apenas ao conteúdo de leis ordinárias, leis complementares e medidas provisórias, não contabilizamos se o Executivo Federal se valeu do poder concedido para produzir benefícios tributários.

Outro ponto importante para ressaltar se refere à interpretação dos dispositivos e à sua equiparação unitária no que diz respeito a seu real valor de renúncia. Um leitor atento pode se perguntar: por que não foi analisado o impacto do dispositivo segundo a sua renúncia específica? Este procedimento deveria ser possível dada a tangibilidade da renúncia tributária. No entanto, não há metodologia adequada para tal ${ }^{10}$. Como já apontamos, as próprias estimativas da Receita Federal sobre a renúncia de receitas são questionadas e já foram indagadas pelo Tribunal de Contas da União.

Assim, neste trabalho fazemos uma equiparação unitária dos dispositivos no que diz respeito a seu real valor de renúncia. Dois dispositivos completamente diferentes em relação a seu impacto sobre a arrecadação das contribuições são tratados de maneira equivalente, por exemplo: um dispositivo que concede isenção do PIS para cooperativas tem o mesmo peso que um dispositivo que isenta o setor farmacêutico desse tributo. Como podemos notar, sem qualquer conhecimento contábil mais profundo sobre o assunto, é muito provável que o dispositivo que concede o benefício ao setor farmacêutico represente uma renúncia muito maior do que o dispositivo dedicado às cooperativas.

Do mesmo modo, é importante destacar que nosso recorte não permite captar manipulações tributárias. Como examinamos somente os benefícios referentes às três contribuições sociais selecionadas (PIS, COFINS e CSLL), não captamos se um benefício é concedido em função do aumento de outro tributo. Ou seja, se por ventura o governo decidiu aumentar a incidência do IPI sobre um setor específico em troca de uma redução da COFINS, não nos interessa saber se a arrecadação tributária como um todo não se alterou. Estamos interessados na presença do benefício concedido em relação à contribuição social que é objeto desta pesquisa.

Por fim, diferenciamos os dispositivos selecionados daqueles que são criados com o objetivo de alterar o texto de dispositivos existentes. Com base no impacto legal do dispositivo criado sobre o arcabouço legislativo pré-existente, encontramos nas leis e medidas provisórias três tipos diferentes de dispositivos: (i) Dispositivos Inovadores: dispositivos que inovam com o objetivo criar uma nova regulação através da concessão de novos benefícios tributários; (ii) Dispositivos Incrementais: dispositivos que se apoiam no arcabouço legal já existente com o objetivo de incrementá-lo; e (iii) Dispositivos Reformadores: dispositivos cujo objetivo é alterar o texto de dispositivos criados anteriormente, seja para revogá-los, ampliá-los ou restringi-los. Neste trabalho selecionamos apenas os tipos (i) e (ii), pois se tratam de dispositivos novos que passam a compor o arcabouço legal, seja para inová-lo ou para incrementá-lo ${ }^{11}$. 


\author{
${ }^{11}$ Estamos trabalhando \\ somente com dispositivos \\ novos. Não contabilizamos \\ dispositivos legais que \\ promovem alterações em \\ dispositivos já criados. $\mathrm{Na}$ \\ construção do banco de dados \\ já iniciamos um trabalho sobre \\ a alteração sofrida por cada \\ dispositivo após a sua criação \\ e pretendemos concluí-lo em \\ outra oportunidade. Exemplos \\ de cada tipo de dispositivo \\ podem ser encontrados em \\ Moreira (2011, Anexo 5). \\ ${ }^{12}$ A Lei de Responsabilidade \\ Fiscal elenca oito tipos \\ diferentes de benefícios \\ tributários cujos parâmetros \\ foram utilizados para a \\ construção de nossas \\ categorias. São eles: 1 . \\ Anistia; 2. Remissão; 3. \\ Subsídio Tributário; 4. Crédito \\ Presumido; 5. Isenção; 6. \\ Redução de Alíquota; 7. \\ Redução da Base de Cálculo; \\ 8. Tratamento Diferenciado.
}

\section{Análise Empírica}

Sob este recorte, vinculado ao impacto inovador ou incremental do dispositivo sobre o arcabouço legal pré-existente, consideramos oito tipos diferentes de benefícios tributários com base no parágrafo primeiro do artigo 14 da Lei de Responsabilidade Fiscal (Lei Complementar 101/2001) ${ }^{12}$.

Além de dispositivos que concedem algum dos oito benefícios tributários previstos, nosso trabalho também se debruça sobre dispositivos que regulam os potenciais beneficiados. A seleção desses dispositivos se faz necessária porque são eles os responsáveis por incluir a possibilidade de setores, produtores ou atividades econômicas específicas se beneficiarem da renúncia de receitas. Ademais, se a concessão de benefícios tributários é importante, tão importante quanto é a regulamentação que permite o acesso a ela.

A despeito dos problemas apontados, consideramos que para responder à nossa questão de pesquisa referente à participação dos diferentes atores no processo decisório da política, a unidade de análise é adequada. Ela não substitui análises que têm como principal unidade de medida o processo legislativo como um todo ou o texto legal em sua integralidade. No entanto, complementando esta unidade de medida, o dispositivo legal funciona como proxy da participação dos atores sobre o texto final. Em relação a este trabalho, o dispositivo legal funciona como proxy da participação dos atores na formulação do conteúdo da política de benefícios tributários referentes ao PIS, à COFINS e à CSLL de 1995 a 2010. Na próxima seção nos dedicamos à análise dos dados.

Vimos na Seção 3 que a estimativa de renúncia de receitas de 1995 a 2010 referente aos benefícios tributários do PIS, da COFINS e da CSLL cresceu de $\mathrm{R} \$ 386$ milhões para R\$ 49 bilhões. Ao longo desse período, 60 processos legislativos deram origem a 1.314 dispositivos que concederam e regularam os benefícios tributários referentes às contribuições selecionadas.

Podemos ver pela Figura 4 uma clara mudança no volume de dispositivos criados de um governo para o outro. Enquanto no governo FHC foram criados

Figura 4 - Evolução da criação de dispositivos que regulam a concessão de benefícios tributários (1995-2010)

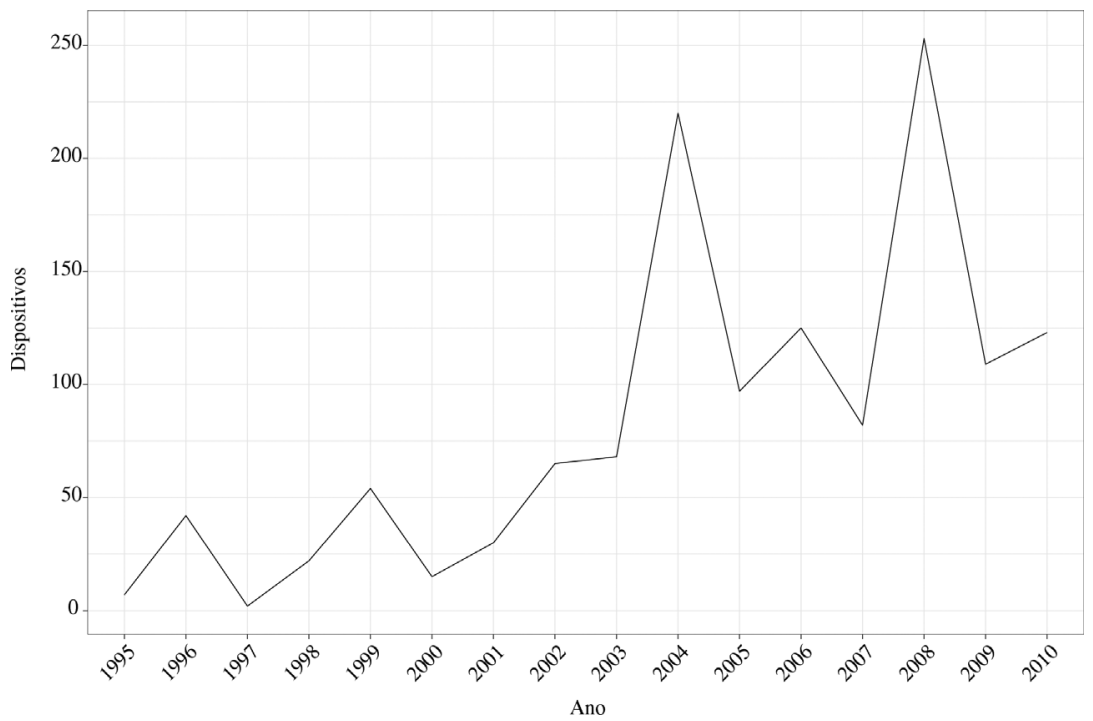

Fonte: Elaboração própria. 
em média 29,6 dispositivos por ano, durante o governo Lula este valor sobe para 134,6 dispositivos por ano.

Apesar da discrepância, com o passar dos anos houve um considerável aumento no número de dispositivos criados pelo governo FHC. Em seu primeiro mandato (1995-1998), foram criados 73 dispositivos por meio de nove processos legislativos, sendo em média 8,1 dispositivos por processo. Já no segundo mandato (1999-2002), foram criados 164 dispositivos que concederam e regularam a concessão de benefícios tributários através de 12 processos legislativos, sendo em média criados 13,7 dispositivos por processo.

No primeiro mandato do presidente Lula foram criados 510 dispositivos através de 13 processos legislativos, em média 39,2 por processo. Valor duas vezes maior do que o que o governo FHC criou em seus oito anos de mandato. $\mathrm{O}$ ano de 2004 apresenta um pico em relação ao período. Neste ano, os 220 dispositivos criados referem-se a oito processos legislativos diferentes, no entanto, 115 (52,3\%) desses dispositivos foram criados pela Lei 10.865 que tinha como propósito principal dar tratamento isonômico às importações através da criação do PIS-Importação e da COFINS-Importação, atendendo a reivindicações do empresariado nacional que se sentia prejudicado pelas regras que estavam em vigor.

Durante o segundo mandato de Lula foram criados 567 dispositivos por meio de 26 processos legislativos, sendo em média 21,8 dispositivos por processo. O ano de 2008 apresenta pico em relação ao período. Nesse caso, nove processos legislativos foram responsáveis por criar os 253 dispositivos, sendo que 129 (51\%) correspondem à Lei Complementar 128, que tratou de incrementar o Estatuto da Micro e Pequena Empresa criado em 2006.

Se os governos do Presidente Fernando Henrique Cardoso e de Luiz Inácio Lula da Silva se diferenciam em relação à agenda de políticas vislumbrada e com respeito ao contexto no qual estavam inseridos, podemos identificar diferentes padrões de atuação dos representantes na concessão de benefícios tributários a setores econômicos do país através do processo legislativo? Em direção à pergunta que este artigo busca responder: em meio ao arcabouço institucional do Presidencialismo de Coalizão Brasileiro, onde reside o poder decisório na formulação dessa política pública?

Nesta seção vamos comparar os mandatos Lula e FHC destacando separadamente os aspectos referentes a cada um. A análise empírica aqui desenvolvida pode ser enquadrada como mais um esforço para a compreensão do processo legislativo nacional na tentativa de averiguar padrões de interação entre os Poderes Executivo e Legislativo.

Muitos trabalhos analisaram os Poderes Executivo e Legislativo de forma uniforme e estritamente dividida pela separação de Poderes. A análise desenvolvida neste artigo se vale dessa separação enquanto recurso analítico, mas não se restringe a ela. É considerado o fato de que estamos diante de um Presidencialismo de Coalizão (Abranches, 1988) e de que a formatação do Poder Executivo tem como finalidade principal a formação de maioria legislativa no Congresso Nacional (Figueiredo \& Limongi, 2002; 1999; 2010; Limongi \& Figueiredo, 1998; 2005). Por isso, ora esses atores são tratados como entidades separadas do ponto de vista formal (institucional), ora analisados do ponto de vista político, separados enquanto situação e oposição. Esta seção será dividida em três partes principais, todas elas evidenciando aspectos empíricos que, ao final, apresentam como os benefícios referentes ao PIS, à COFINS e à CSLL são concedidos. 


\section{V.1. Qual o volume de participação dos atores envolvidos no processo decisório?}

Ao analisar a participação legislativa sob a nova Constituição, Freitas (2010) destaca que "a literatura, ao enfatizar a dinâmica de centralização dos trabalhos legislativos, acaba não observando a potencial participação objetiva que o Legislativo tem sobre a legislação aprovada, diminuindo, assim, sua efetiva contribuição no processo de produção de leis" (2010, p.15). Para este autor, os estudos que analisam a governabilidade brasileira dedicam à formatação dos Ministérios o sucesso legislativo do Presidente da República, sem assumir que a governabilidade se dá em termos substantivos, ou seja, através da participação dos parlamentares na produção de políticas públicas. Levando em consideração o trabalho de Freitas (2010) e considerando a separação dos Poderes do ponto de vista formal, na análise dos dispositivos que ganharam força de lei, podemos encontrar a participação dos atores durante os governos FHC e Lula (Tabela 2).

Por meio de 21 processos legislativos, no governo FHC foram criados 237 dispositivos que concederam e regularam a concessão de benefícios tributários referentes ao PIS, à COFINS e à CSLL. Este montante equivale respectivamente a $35,0 \%$ dos processos legislativos e $18,0 \%$ dos dispositivos criados entre 1995 e 2010.

Valendo-se de seu poder de agenda, no governo FHC o Poder Executivo foi autor de $18(85,7 \%)$ dos 21 processos legislativos e responsável pela autoria exclusiva de $85,7 \%$ do total de dispositivos do período, enquanto o Poder Legislativo foi autor de três dos processos legislativos que concederam benefícios tributários e criou exclusivamente apenas $11,8 \%$ dos dispositivos. O restante dos dispositivos foi criado de forma conjunta, ou seja, ambos os Poderes contribuíram para seu texto final.

Como no governo anterior, durante o governo Lula o Poder Executivo também se valeu de seu poder de agenda e foi autor de 87,2\% (34 do total de 39) dos projetos de lei que concederam e regularam benefícios tributários. No entanto, dos 1.077 dispositivos criados pelos 39 processos legislativos do governo Lula, o Executivo Federal foi exclusivamente responsável por apenas 29,8\% deles (321 dispositivos), enquanto 66,1\% (712 dispositivos) foram exclusivamente criados pelo Poder Legislativo. Outros 44 dispositivos $(4,1 \%)$ foram criados de forma conjunta pelos atores. O teste de aderência apresenta evidências de que a distribuição observada nos dispositivos selecionados durante o governo Lula é estatisticamente diferente da distribuição esperada com os dados que temos sobre o governo FHC.

Vemos pela Figura 5 que há uma alternância no volume de participação dos atores ao longo do tempo e também que o Poder Legislativo participou relativamente mais do que o Poder Executivo na formulação da política.

Tabela 2 - Autoria dos Dispositivos (\%)

\begin{tabular}{lcc}
\hline Autoria & Governo FHC & Governo Lula \\
\hline Exclusiva do Poder Executivo & $203(85,7)$ & $321(29,8)$ \\
Exclusiva do Poder Legislativo & $28(11,8)$ & $712(66,1)$ \\
Conjunta & $6(2,5)$ & $44(4,1)$ \\
Total & $237(100,0)$ & $1077(100,0)$ \\
\hline
\end{tabular}

Fonte: Elaboração própria.

$\chi 2=3089.843, \mathrm{df}=2, \mathrm{p}$-value $=0,000$. 
Figura 5 - Autoria de dispositivos por ano (1995-2010)

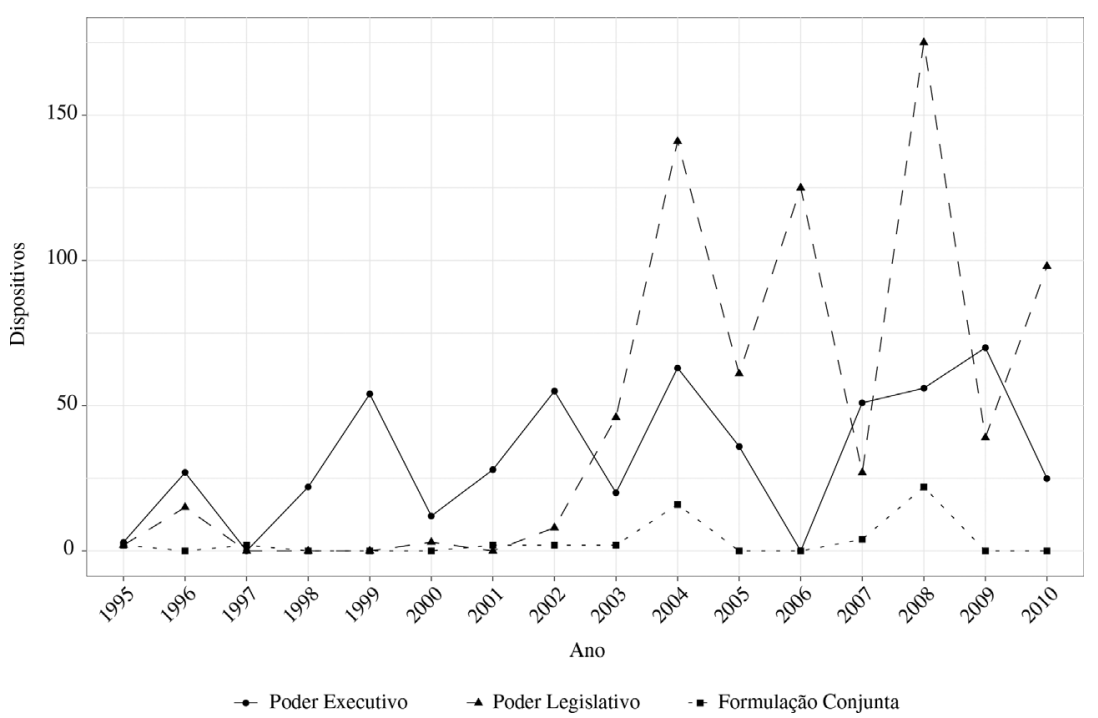

Fonte: Elaboração própria.

Se retomarmos a discussão feita na Seção 2 a respeito do modelo distributivista de análise, já é possível concluir que se o comportamento dos políticos brasileiros para a formulação da política de benefícios tributários é motivado pura e simplesmente pela arena eleitoral (Ames, 1995b; 2002; Crisp \& Desposato, 2004; Crisp \& Ingall, 2002; Mainwaring, 1991; 1999; Pereira \& Mueller, 2002), há algo de estranho quando comparamos os governo FHC e Lula. No primeiro, vemos que é preponderante a participação do Poder Executivo na autoria de dispositivos e o Poder Legislativo pouco interfere sobre o conteúdo da política. Já no segundo, identificamos que há uma inversão de participação, pois o Legislativo Federal se torna o responsável pela maior parte do conteúdo legislativo que dá origem às leis que concedem benefícios tributários.

Aqui, portanto, já podemos contrapor o indicativo de que a concessão de benefícios tributários faria parte do quid pro quo existente entre representantes eleitos e grupos de interesse que se beneficiariam da renúncia de receitas (Dever Jr., 2008; Graetz, 2007; Mancuso, Gonçalves \& Mencarini, 2010) uma vez que o volume de participação dos atores nos diferentes governos não é ao menos parecido. Contudo, a apresentação do volume de participação dos Poderes pode suscitar dúvidas que ainda validam a suposição de que a guinada participativa do legislativo reflita exatamente a necessidade de os parlamentares beneficiarem individualmente grupos econômicos de seu interesse.

Para avançarmos na análise de onde reside o poder decisório na formulação da política de benefícios tributários, vejamos se a participação legislativa não ficou concentrada a poucas oportunidades diante de todo o poder de agenda do Poder Executivo e como se deu sua participação por processo legislativo em cada um dos governos.

Podemos encontrar ao menos dois resultados quando controlamos a participação dos atores por processo legislativo. No primeiro, que chamamos de Participação Isolada, um dos Poderes é o responsável único pela autoria de todos os dispositivos que concederam benefícios tributários num processo legislativo finalizado, indicando, obviamente, que nenhum dispositivo de autoria do outro Poder chegou a ser aprovado no texto final. No caso do Poder Executivo, em dois tipos de processos legislativos isto pode ocorrer: (i) no caso específico de medidas provisórias anteriores à Emenda Constitucional 32 de 
2001 que não chegaram a ser apreciadas pelo Congresso Nacional; (ii) ou no caso de projetos de lei ou medidas provisórias editadas que os parlamentares aprovaram sem alterar o texto que receberam ou sem adicionar algum dispositivo legal que concedesse ou regulasse a concessão de benefícios tributários. No caso do Poder Legislativo, isto pode ocorrer em outras duas ocasiões: (i) no caso de o Poder Executivo ter encaminhado projeto de lei ou editado medida provisória, cujo texto não criava novos dispositivos e o Congresso Nacional tratou de incrementar seu conteúdo incluindo dispositivos que concederam ou regularam a concessão de benefícios tributários que não foram vetados pelo Presidente da República; (ii) ou no caso de projetos de lei dos próprios parlamentares que concederam e regularam a concessão de benefícios tributários e também não foram vetados.

No segundo, que chamamos de Participação Complementar, o Poder Executivo e o Poder Legislativo atuam sobre o conteúdo de uma norma num mesmo processo legislativo, criando de forma exclusiva (Tipos 1 ou 2, Tabela 2 da Seção 4) ou conjunta (Tipo 3, Tabela 2 da Seção 4) dispositivos que foram posteriormente sancionados pelo Presidente da República. Há duas situações nas quais isso pode acontecer: (i) quando uma medida provisória editada ou projeto de lei encaminhado ao Congresso Nacional cria dispositivos e ao ser apreciado pelos parlamentares é incrementado com dispositivos propostos pelos legisladores; (ii) quando uma medida provisória editada ou projeto de lei encaminhado ao Congresso Nacional cria dispositivos e ao ser apreciado pelos parlamentares tem seu texto literalmente alterado pelos legisladores.

Com base no resultado apresentado por processo legislativo, vemos que tanto no que diz respeito ao tipo de participação pelo número de processos legislativos como em relação ao volume de dispositivos criados por tipo de participação, há evidências suficientes de que as distribuições encontradas no governo Lula são diferentes das verificadas no governo FHC (Tabela 3).

Vemos pela Tabela 3 que durante o governo FHC o Poder Executivo não atuou em três $(14,3 \%)$ dos 21 processos legislativos, através dos quais o Legislativo federal criou 4,6\% dos dispositivos deste governo. Contudo, ele atuou de forma complementar com o Poder Legislativo em outros quatro processos legislativos que deram origem a $85(35,9 \%)$ dispositivos que concederam e regularam a concessão dos benefícios tributários referentes ao PIS, à COFINS e à CSLL neste período. Apesar da participação complementar e da participação isolada do Legislativo, o Poder Executivo atuou sozinho em 66,7\% dos processos legislativos, criando através desses processos $59,5 \%$ dos dispositivos do período. Temos, portanto, uma atuação preponderante do Poder Execu-

Tabela 3 - Participação do Poder Executivo (\%)

\begin{tabular}{lccccc}
\hline \multirow{2}{*}{ Participação } & \multicolumn{2}{c}{ Governo FHC } & & \multicolumn{2}{c}{ Governo Lula } \\
\cline { 2 - 3 } \cline { 5 - 6 } & NPLs & NDisp & & NPLs & NDisp \\
\hline Isolada & $14(66,7)$ & $141(59,5)$ & & $12(30,8)$ & $102(9,5)$ \\
Complementar & $4(19,0)$ & $85(35,9)$ & & $16(41,0)$ & $620(57,6)$ \\
Não Participou & $3(14,3)$ & $11(4,6)$ & & $11(28,2)$ & $355(32,9)$ \\
Total & $21(100,0)$ & $237(100,0)$ & & $39(100,0)$ & $1077(100,0)$ \\
\hline
\end{tabular}

Fonte: Elaboração própria. NPLs: Número de Processos Legislativos; NDisp: Número de dispositivos.

NPLs $\chi 2=22.7179, \mathrm{df}=2$, p-value $=0,000$.

NDisp $\chi 2=2455.545, \mathrm{df}=2, \mathrm{p}$-value $=0,000$. 
tivo na formulação da política, seja pela criação de dispositivos, seja pela atuação isolada nos processos legislativos.

Já no governo Lula, vemos que apesar do poder de agenda do Poder Executivo, o Poder Legislativo se mostrou bastante ativo na formulação da política de benefícios tributários referentes ao PIS, à COFINS e à CSLL. Como mostra a Tabela 3, em 16 processos legislativos (41,0\% de 39) os Poderes atuaram de forma complementar, e em 11 processos legislativos o Poder Legislativo foi sozinho responsável por criar os dispositivos que regularam a concessão de benefícios tributários referentes às contribuições selecionadas.

Diferente do que vimos no governo FHC, quando o Poder Executivo atuou sozinho em 66,7\% dos processos, durante os mandatos do Presidente Lula o Poder Executivo só participou de forma isolada em 30,8\% dos projetos de lei que regularam a concessão de benefícios tributários. Todos os outros 27 projetos $(69,2 \%)$ contaram com a participação propositiva do Poder Legislativo.

Temos, assim, mais uma grande diferença em relação aos dois governos analisados, já que além da guinada participativa dos legisladores na produção de conteúdo da política pública pela criação de dispositivos, constatamos um aumento de participação complementar à matéria encaminhada pelo Executivo. Isto nos remete diretamente ao trabalho de Freitas (2010) e seu argumento de que a governabilidade também se dá em termos substantivos. Desse modo, na busca por mapear onde reside o poder decisório a respeito do conteúdo da política de benefícios tributários, podemos indagar: como se deu a atuação dos poderes?

V.2. Como se deu a atuação dos Poderes?

Através da divisão formal entre os Poderes, analisamos os procedimentos formais pelos quais os dispositivos propostos por cada um dos Poderes foram aprovados. Analisamos somente os dispositivos de autoria exclusiva (Tipos 1 ou 2, Tabela 2 da Seção 4) por tipo de processo legislativo (medida provisória, processo legislativo de lei ordinária ou processo legislativo de lei complementar).

V.2.1. Atuação do Poder Executivo

No governo FHC, o Poder Executivo foi autor de 18 processos legislativos que regularam a concessão de benefícios tributários. Conforme a Tabela 4 nos apresenta, o Poder Executivo criou 82,3\% de seus dispositivos através de medidas provisórias e, mais do que isso, no período em que a Emenda Constitucional 32 ainda não havia sido apreciada, 95,3\% dos dispositivos de sua autoria

Tabela 4 - Dispositivos de autoria exclusiva do Poder Executivo por Espécie Normativa (\%)

\begin{tabular}{lccccc}
\hline Dispositivo & \multicolumn{3}{c}{ Governo FHC } & & Governo Lula \\
\cline { 2 - 3 } & Antes EC32 & Após EC32 & Total FHC & & Total Lula \\
\hline MP & $123(95,3)$ & $44(59,5)$ & $167(82,3)$ & & $295(91,9)$ \\
LO & $6(4,7)$ & $30(40,5)$ & $36(17,7)$ & & $26(8,1)$ \\
LC & $0(0,0)$ & $0(0,0)$ & $0(0,0)$ & & $0(0,0)$ \\
Total & $129(100,0)$ & $74(100,0)$ & $203(100,0)$ & & $321(100,0)$ \\
\hline
\end{tabular}

Fonte: Elaboração própria. MP: Medida Provisória; LO: Lei Ordinária. LC: Lei Complementar. 
${ }^{13}$ Consideramos vetados somente os processos legislativos cujo conteúdo vetado continha dispositivos legais referentes à concessão ou regulação de benefícios tributários ligados às contribuições selecionadas. Assim, é possível que outros projetos de lei tenham sido vetados, mas, como o conteúdo vetado não se encontra no escopo desta pesquisa, eles não foram contabilizados. exclusiva foram criados por esta via. Após sua promulgação, menos de $60 \%$ dos dispositivos criados por esse governo ganharam força de lei por esta espécie normativa.

Além disso, até a edição da Emenda Constitucional 32, em 11 de setembro de 2001, o governo FHC se valeu da prerrogativa de editar e de reeditar medidas provisórias que concederam benefícios tributários e assim evitar, por certo tempo, a apreciação parlamentar. Para se ter uma ideia de como essa estratégia foi utilizada, cada dispositivo criado por medida provisória anterior à EC 32/2001 foi em média 16,5 vezes reeditado.

Já no Governo Lula, 91,9\% de seus dispositivos foram criados através de medidas provisórias. Independente da manutenção da estratégia do Poder Executivo em ver aprovados os seus dispositivos com a edição de medidas provisórias, cabe ressaltar que o governo Lula não pôde se valer da possibilidade de reeditá-las. Deste modo, o governo Lula inicia sua trajetória de produção das políticas de benefícios tributários muito mais propenso a necessitar da atividade parlamentar do que seu antecessor (Tabela 4).

Outro recurso de participação do qual o Poder Executivo pode se valer para moldar a política de benefícios tributários conforme seus interesses é a possibilidade de uso de seu poder de veto (parcial ou total) previsto nos parágrafos $1^{\circ} \mathrm{e}$ $2^{\circ}$ do artigo 66 da Constituição Federal. Através dele é possível ao Presidente da República impedir a aprovação de dispositivos propostos e aprovados pelos parlamentares.

Vimos anteriormente que os parlamentares pouco participaram da autoria de dispositivos ao longo do governo FHC. Deste modo, poderíamos supor que a falta de sucesso desse ator estivesse atrelada ao uso do poder de veto do Presidente da República. No entanto, durante os mandatos de Fernando Henrique Cardoso, o poder de veto não foi utilizado em nenhum momento para barrar dispositivos propostos por parlamentares e foram incluídos nos projetos de lei para sanção presidencial após sua tramitação no Congresso Nacional.

Já no governo Lula, sabendo que o Poder Legislativo participou mais do que o Poder Executivo, dos 39 processos legislativos, 15 que tiveram dispositivos criados por parlamentares foram vetados total ou parcialmente pelo Presidente da República ${ }^{13}$. Sob o respaldo do Ministério da Fazenda, o Presidente Lula impediu que a participação parlamentar fosse maior em $38,5 \%$ dos processos legislativos criados durante o seu mandato, vetando 140 dispositivos.

Apesar de o dado acima levantar dúvidas sobre a capacidade de coordenação entre o Poder Executivo e o Poder Legislativo, o fato é que podemos atribuir o uso do poder de veto durante o governo Lula para a formulação da política de benefícios tributários ao expressivo aumento na participação parlamentar na autoria de dispositivos em comparação ao governo anterior.

Ademais, uma análise mais apurada dos dispositivos vetados revela que 71,4\% (100 dispositivos) contaram com a participação de representantes de partidos que não compunham a coalizão governista no momento de sua apresentação. Se o Poder Executivo se valeu do uso constitucional de seu poder de veto para moldar a formulação da política de benefícios tributários de acordo com seus interesses, fez isso vetando principalmente o conteúdo legislativo proposto por membros de partidos que não compunham a base governista.

A necessidade de vetar dispositivos, principalmente aqueles propostos por parlamentares pertencentes à oposição, reforça os indícios de que a guinada participativa do legislativo reflete a possibilidade de os parlamentares utilizarem a janela de oportunidade criada pelo Executivo Federal para beneficiar individualmente grupos econômicos específicos. Já sabendo que a oposição 
buscou e conseguiu incluir conteúdo legislativo de seu interesse no texto apreciado pelo Congresso Nacional, podemos nos perguntar como se deu o processo decisório dos dispositivos no interior do Poder Legislativo.

\section{V.2.2. Atuação do Poder Legislativo}

Durante o governo FHC, sabemos que o Poder Legislativo é responsável exclusivo por apenas 11,8\% (28 de 237) dos dispositivos criados no período e participou de sete $(33,3 \%)$ dos 21 processos legislativos. Apesar da prerrogativa constitucional de legislar sobre matéria tributária ser do Presidente da República (art. 61, §1, II, b), o Poder Legislativo ainda é autor de três dos sete processos legislativos no qual teve participação na criação de dispositivos.

Sabendo que até 11 de setembro de 2001 o Poder Executivo podia reeditar medidas provisórias por tempo indeterminado e que seus dispositivos foram em média 16 vezes reeditados. Como fizemos para analisar a participação do Poder Executivo, podemos inferir que a mudança institucional teve algum impacto na participação parlamentar? Podemos ver que com a EC 32/2001, enquanto o Poder Executivo aumentou a autoria de dispositivos através de projetos de lei ordinária, o Poder Legislativo passou a criar mais dispositivos através da apreciação das medidas provisórias editadas. Ademais, é necessário ressaltar que todos os 17 dispositivos criados por este ator em processos legislativos iniciados por medidas provisórias foram formulados sobre medidas provisórias que não foram reeditadas nenhuma vez e seguiram direto para a apreciação parlamentar.

Diferente do que ocorreu no governo FHC, vimos que nos mandatos do Presidente Lula o Poder Legislativo foi responsável pela grande maioria dos dispositivos que regularam a concessão de benefícios tributários referentes às contribuições selecionadas. Este Poder criou de forma exclusiva o equivalente a 66,1\% (712) dos 1.077 dispositivos do período e participou de 69,2\% (27 de 39) dos processos legislativos, sendo inclusive autor de quatro projetos de lei do qual participou. Durante o governo Lula os parlamentares mantiveram o padrão de atuação identificado após a promulgação da EC 32/2001. Vemos pela Tabela 5 que mais de $60 \%$ dos dispositivos criados por este ator foram criados sobre a tramitação de MPs. No entanto, ganha destaque a participação do Poder Legislativo na autoria de dispositivos sobre processos legislativos de leis complementares.

Antes que o uso de processos legislativos de leis complementares possa parecer uma estratégia parlamentar para a aprovação de seus interesses ao valer-se da maior rigidez que o rito deste tipo de processo pressupõe ${ }^{14}$, é

${ }^{14}$ Enquanto a aprovação de leis ordinárias necessita de apenas uma maioria simples com a presença de ao menos a maioria dos membros de cada Casa Legislativa (art. $47 \mathrm{da}$ $\mathrm{CF} / 88$ ), o processo legislativo de leis complementares exige aprovação por maioria absoluta (art. 69 da CF/88), ou seja, necessita da aprovação da maioria de seus membros. importante destacar que dos 263 dispositivos criados por esta via, $260(98,9 \%)$

Tabela 5 - Dispositivos de autoria exclusiva do Poder Legislativo por Espécie Normativa $(\%)$

\begin{tabular}{lccccc}
\hline \multirow{2}{*}{ Dispositivo } & \multicolumn{3}{c}{ Governo FHC } & & Governo Lula \\
\cline { 2 - 4 } & Antes EC32 & Após EC32 & Total FHC & & Total Lula \\
\hline MP & $9(45,0)$ & $6(75,0)$ & $15(53,6)$ & & $447(62,9)$ \\
LO & $5(25,0)$ & $2(25,0)$ & $7(25,0)$ & & $2(0,2)$ \\
LC & $6(30,0)$ & $0(0,0)$ & $6(21,4)$ & & $263(36,9)$ \\
Total & $20(100,0)$ & $8(100,0)$ & $28(100,0)$ & & $712(100,0)$ \\
\hline
\end{tabular}

Fonte: Elaboração própria. MP: Medida Provisória. LO: Lei Ordinária. LC: Lei Complementar.

$\chi 2=265.2212, \mathrm{df}=2, \mathrm{p}$-value $=0,000$. 
estão vinculados à criação do Estatuto da Micro e Pequena Empresa no ano de 2006, que regulamenta o inciso IX do artigo 170 da Constituição Federal. O processo legislativo desta política estava previsto no artigo $1^{\circ}$ da Emenda Constitucional 42, de dezembro de 2003, cujo texto pressupunha a tramitação de projeto de lei complementar.

Deste modo, não é possível atribuir a autoria de dispositivos via processo legislativo de lei complementar a uma estratégia elaborada pelos parlamentares para emplacar seus interesses. No entanto, devemos destacar que após a promulgação da EC 32/2001 o poder de agenda do Poder Executivo não é condição suficiente para suprimir as demandas e iniciativas parlamentares. Como vimos, não é por meio do domínio da agenda que se neutraliza o restante do processo legislativo.

O Poder Legislativo participa de forma propositiva e objetiva do processo de formulação da política de benefícios tributários, residindo nele parcela relevante do conteúdo aprovado. Este achado contraria conclusões que afirmam ter o Congresso Nacional um índice muito baixo de produção legislativa (Moisés, 2011). O poder de agenda do Executivo pode coibir a iniciativa legislativa do Congresso, mas não é suficiente para inibir a participação parlamentar sobre as matérias em pauta e o conteúdo posteriormente aprovado.

Com relação ao Poder Legislativo, também verificamos a configuração partidária na autoria exclusiva de dispositivos. Em cada Casa legislativa analisamos os textos de emendas individuais, projetos apensados, destaques e substitutivos com objetivo de averiguar os partidos dos parlamentares cujas propostas de dispositivos obtiveram sucesso e se estes partidos compunham a coalizão governista no momento em que foram propostos os dispositivos posteriormente sancionados. Para tanto, como pode ser visto na Tabela 6, criamos três categorias para classificar se os dispositivos foram propostos por partidos da coalizão ou não: Total, Parcial e Nula.

A primeira, chamada de Total, se refere a dispositivos que foram propostos por partidos que compunham a coalizão governista no momento em que seu texto passa a fazer parte do projeto a ser aprovado. Neste caso, quando mais de um parlamentar propôs um mesmo dispositivo, consideramos que o dispositivo pertence a uma proposta da coalizão governista quando todos os partidos dos parlamentares que o propuseram a ela pertencem. A segunda, chamada de Parcial, envolve a participação de parlamentares membros de partidos da coalizão governista e de parlamentares de partidos que não pertenciam a ela. Nesta categoria consideramos, por exemplo, os casos em que um dispositivo presente numa emenda individual de um parlamentar da oposição é aprovado por um relator da situação e, assim, passa a compor o texto legislativo que será apreciado. Por fim, temos a categoria Nula, quando nenhum parlamentar membro de partidos da coalizão governista participa formalmente da apresentação de um dispositivo posteriormente aprovado.

Tabela 6 - Configuração Partidária da Participação do Poder Legislativo na autoria exclusiva de Dispositivos (\%)

\begin{tabular}{|c|c|c|c|c|c|c|}
\hline \multirow[t]{2}{*}{ Coalizão } & \multicolumn{3}{|c|}{ Governo FHC } & \multicolumn{3}{|c|}{ Governo Lula } \\
\hline & CD & SF & Total & CD & SF & Total \\
\hline Total & $26(92,9)$ & $0(0,0)$ & $26(92,9)$ & $301(54,9)$ & $162(98,8)$ & $463(65,0)$ \\
\hline Parcial & $2(7,1)$ & $0(0,0)$ & $2(7,1)$ & $82(15,0)$ & $0(0,0)$ & $82(11,5)$ \\
\hline Nula & $0(0,0)$ & $0(0,0)$ & $0(0,0)$ & $165(30,1)$ & $2(1,2)$ & $167(23,5)$ \\
\hline Total & $28(100,0)$ & $0(100,0)$ & $28(100,0)$ & $548(100,0)$ & $164(0,0)$ & $712(0,0)$ \\
\hline
\end{tabular}

Fonte: Elaboração própria. CD: Câmara dos Deputados. SF: Senado Federal. 
${ }^{15}$ Para uma análise detalhada da participação da oposição ver (Moreira, 2011).
Durante o governo FHC, a participação do Poder Legislativo na formulação da política de benefícios tributários se deu no bojo da coalizão governista. Com exceção do PL 6.770/2002, que criou dois dispositivos e contou com a participação do Partido dos Trabalhadores (PT) na autoria da Emenda Substitutiva de Plenário num momento em que, curiosamente, a coalizão governista era minoria parlamentar, todos os outros dispositivos foram criados por meio de partidos que compunham a coalizão governista. Ademais, todos os dispositivos criados foram propostos na Câmara dos Deputados, sem que houvesse participação dos senadores na formulação de dispositivos posteriormente aprovados.

Com respeito ao governo Lula, 35\% (249) dos dispositivos foram criados com a participação de parlamentares da oposição durante o processo legislativo. Diferente do governo FHC, quando a participação do PT na coautoria da emenda substitutiva de plenário que modificou o PL 6.770/2002 se deu num momento em que a coalizão governista era minoria tanto na Câmara dos Deputados como no Senado Federal, no caso do governo Lula os partidos que não compunham a coalizão governista participaram mesmo com esta coalizão tendo a maioria nas duas Casas durante as tramitações dos projetos de lei.

Outra diferença na atuação parlamentar durante a formulação da política de benefícios tributários no governo Lula está na participação das Casas Legislativas. Enquanto no governo FHC todos os dispositivos criados pelo Poder Legislativo foram propostos por Deputados Federais, no governo Lula o Senado Federal aparece como propositor de 23,0\% (164) dos dispositivos criados no período. Basicamente, a atuação da segunda Casa se deu a partir da apreciação dos textos encaminhados pela Câmara dos Deputados e o incremento de poucos dispositivos de seu interesse direto. A análise dedicada à atuação do Poder Legislativo reduz as expectativas referentes à possibilidade de os parlamentares utilizarem a janela de oportunidade criada pelo Executivo Federal para beneficiar individualmente grupos econômicos específicos, pois, como vimos, a grande maioria de dispositivos é criada pela base aliada do governo, sendo pequena a participação da oposição ${ }^{15}$.

Para pôr fim a qualquer especulação a este respeito, através da análise detalhada dos processos legislativos, verificamos a condição de participação dos parlamentares cujos dispositivos propostos foram posteriormente aprovados e cruzamos esta informação com a configuração partidária na autoria exclusiva de dispositivos com objetivo de averiguar se os partidos dos parlamentares cujas propostas de dispositivos obtiveram sucesso compunham a coalizão governista no momento em que foram propostos os dispositivos posteriormente sancionados. As categorias de condição de participação são as seguintes: Relatoria, Relatoria+PLA e Relatoria +Parlamentar.

No caso da Relatoria, dispositivos propostos por parlamentares que ocupavam postos de relatoria. Autoria: dispositivos apresentados por parlamentares que foram autores de projetos de lei. Coautoria: dispositivos elaborados em coautoria de projetos de lei. No caso da Relatoria+PLA, dispositivos que, além de contarem com a aceitação dos relatores do processo legislativo, foram também apresentados por parlamentares autores de projetos de lei que foram apensados à matéria em trâmite. Por sua vez, no caso da Relatoria+Parlamentar, dispositivos que, além de serem aceitos pelos relatores dos processos legislativos, também estavam presentes nas emendas individuais apresentadas.

Tanto no governo FHC como no governo Lula a interferência dos parlamentares sobre o conteúdo legislativo esteve diretamente atrelada a postos institucionais centralizadores de poder ocupados durante o processo legislativo (Tabela 7). Assim, é possível refutar a hipótese de que os dispositivos criados pelos parlamentares sejam resultado direto do anseio individual de deputados e 
Tabela 7 - Condição de Participação dos Parlamentares

\begin{tabular}{|c|c|c|c|c|c|c|c|c|}
\hline \multirow[t]{2}{*}{ Condição } & \multicolumn{4}{|c|}{ Governo FHC } & \multicolumn{4}{|c|}{ Governo Lula } \\
\hline & Total & Parcial & Nula & Total NDisp & Total & Parcial & Nula & Total NDisp \\
\hline Relatoria & $24(92,3)$ & $0(0,0)$ & $0(0,0)$ & $24(85,8)$ & $442(95,5)$ & $0(0,0)$ & $160(95,8)$ & $602(84,5)$ \\
\hline Autoria & $2(7,7)$ & $0(0,0)$ & $0(0,0)$ & $2(7,1)$ & $0(0,0)$ & $0(0,0)$ & $0(0,0)$ & $0(0,0)$ \\
\hline Coautoria & $0(0,0)$ & $2(100,0)$ & $0(0,0)$ & $2(7,1)$ & $3(0,6)$ & $15(18,3)$ & $0(0,0)$ & $18(2,6)$ \\
\hline Relatoria+PLA & $0(0,0)$ & $0(0,0)$ & $0(0,0)$ & $0(0,0)$ & $3(0,6)$ & $24(29,3)$ & $0(0,0)$ & $27(3,8)$ \\
\hline $\begin{array}{l}\text { Relatoria+Parla } \\
\text { mentar }\end{array}$ & $0(0,0)$ & $0(0,0)$ & $0(0,0)$ & $0(0,0)$ & $15(3,3)$ & $43(52,4)$ & $7(4,2)$ & $65(9,1)$ \\
\hline Total & $26(100,0)$ & $2(100,0)$ & $0(0,0)$ & $28(100,0)$ & $463(100,00)$ & $82(100,0)$ & $167(100,0)$ & $712(100,0)$ \\
\hline
\end{tabular}

Fonte: Elaboração própria. NDisp: Número de dispositivos.

senadores com relação a suas perspectivas eleitorais, mesmo quando selecionamos os dispositivos criados pelos membros dos partidos da coalizão governista.

Os resultados da Tabela 7 mostram que além da autoria de dispositivos do Poder Legislativo estar concentrada na base que dá apoio ao governo, no interior da coalizão governista é o acesso a postos centrais do processo legislativo que aumenta o poder de interferência direta dos parlamentares sobre o conteúdo do texto que é apreciado. Deste modo, podemos refutar a hipótese de que a política de concessão de benefícios tributários referentes ao PIS, à COFINS e à CSLL é resultado da atuação individual dos parlamentares brasileiros, mesmo quando constatamos a preponderância do Poder Legislativo na formulação do conteúdo da política. Todos os indícios que sustentavam a possibilidade dos parlamentares agirem segundo o modelo distributivista, na verdade, apontavam para a configuração do modelo partidário.

\section{Considerações Finais}

A análise empírica apresentou ao menos cinco conclusões importantes. A primeira mostra que a alternância de partidos no governo foi responsável por uma mudança na agenda de políticas e proporcionou um aumento significativo no volume de benefícios tributários concedidos. A esse respeito, verificou-se que o aumento no volume de benefícios tributários concedidos é acompanhado pela produção de conteúdo legislativo que concede novos benefícios tributários.

A segunda conclusão expõe que, independente da alternância de partidos no governo, o Poder Executivo valeu-se mais da estratégia de criar dispositivos de seu interesse pela edição de medidas provisórias do que por meio de outros tipos de processos legislativos. Tal aspecto segue em linha com as análises que ressaltam a força do Poder Executivo em pautar a agenda legislativa e em inibir a participação legislativa sobre o conteúdo do texto já encaminhado, uma vez que, ao ganhar força de lei, os custos de qualquer mudança no texto publicado se tornam altos.

Contudo, nossa terceira conclusão apresenta que o poder de agenda do Executivo Federal não é suficiente para impedir o protagonismo do Poder Legislativo sobre o conteúdo de formulação da política pública. O Legislativo Federal inclui sobre o texto encaminhado uma agenda própria de incentivos fiscais. Se, de um lado, a edição de medidas provisórias aumenta o custo político de qualquer mudança no texto já publicado, de outro, abre uma janela de oportunidade para a inclusão de conteúdo formulado no âmbito do Congresso Nacional. Respondendo parcialmente nossa questão de pesquisa, no Legisla- 
tivo Federal também reside poder decisório de formulação do teor da política de concessão de benefícios tributários.

Em linha com trabalhos apresentados, em quarto lugar mostramos que é míope adotar como estrutura de análise a separação dicotômica entre os poderes. Diante da nossa pergunta de pesquisa: em meio ao arcabouço institucional do Presidencialismo de Coalizão Brasileiro, onde reside o poder decisório na formulação dessa política pública? A resposta correta é: na coalizão governista. Em outras palavras, longe de se restringir ao Poder Executivo e à formatação de Ministérios, o poder decisório a respeito da política de benefícios tributários ultrapassa a separação dos poderes e é em grande extensão compartilhado por forças políticas presentes no Executivo e no Legislativo Federais.

Por fim, para sustentar a resposta à nossa pergunta de pesquisa, não encontramos na formulação da política de benefícios tributários referentes ao PIS, à COFINS e à CSLL a atuação individual dos parlamentares. Nos dois governos analisados a interferência dos parlamentares sobre o conteúdo legislativo esteve diretamente atrelada ao pertencimento à base governista e à ocupação de postos institucionais de poder durante o processo decisório. Vimos que o processo de formulação da política de benefícios tributários é concentrado, permitindo o acesso de alguns (poucos) parlamentares ao conteúdo da política e, assim, mostramos que outras variáveis, para além de incentivos oriundos do sistema eleitoral, influenciam o comportamento dos representantes brasileiros e a aquisição de benefícios por parte de setores e atividades da economia nacional.

As conclusões empíricas deixam de lado a hipótese de que a formulação da política de benefícios tributários seja um alicerce do possível quid pro quo existente entre políticos e grupos de interesse. Estes vínculos até podem existir, mas o fato é que de 1995 a 2010 a formulação da política de benefícios tributários referente ao PIS, à COFINS e à CSLL esteve fortemente atrelada ao controle do governo e se sustentou com base na centralização dos trabalhos enquanto esteve sob a análise do Poder Legislativo. Se nossa análise pode apontar para um padrão de como se concretiza a relação entre Estado e grupos de interesse no Brasil, ao invés de ser individualmente concretizada, esta pesquisa aponta no sentido de dizer que esta relação é partidariamente construída. Logo, se há algum tipo de conexão eleitoral ou de quid pro quo, nossa aposta é de que esta deve ser pensada em termos partidários e não estritamente pessoais.

Davi Cordeiro Moreira (davi.moreira@gmail.com) é Doutor em Ciência Política pela Universidade de São Paulo e Professor Adjunto da Escola de Relações Internacionais da Fundação Getúlio Vargas (FGV-São Paulo).

\section{Referências}

Abranches, S.H. (1988) Presidencialismo de Coalizão: O dilema institucional brasileiro. Dados, 31(1), pp.5-34.

Alesina, A., Hausmann, R., Hommes, R. \& Stein E. (1999) Budget Institutions and Fiscal Performance in Latin America. Journal of Development Economics, 59(2), pp. 253-273. DOI: 10.1016/S0304-3878(99)00012-7

Ames, B. (1995a) Electoral Rules, Constituency Pressures, and Pork Barrel: Bases of Voting in the Brazilian Congress. The Journal of Politics, 57(2), pp.324-343. DOI: 10.2307/2960309

Ames, B. (1995b) Electoral Strategy under Open-List Proportional Representation. American Journal of Political Science, 39(2), pp.406-433. DOI: 10.2307/2111619

Ames, B. (2002) The Deadlock of Democracy in Brazil. Ann Arbor: University of Michigan Press. DOI: 10.3998/mpub.23045

Araújo, É.A. (2005) Análise das Contribuições Sociais no Brasil. Documento elaborado no âmbito do Convênio CEPAL/IPEA, LC/BRS/R.158. [online]. Brasília: Comissão Econômica para a América Latina e o Caribe - CEPAL, pp. 4-101. Disponível em: $<$ https://silo.tips/downloadFile/cepal-comissao-economica-para-a-america-latina-e-o-caribe-escritorio-no-brasil-a>. Acesso em 25 de set. 2020.

Arnold, R.D. (1990) The Logic of Congressional Action. New Haven \& London: Yale University Press. 
Baron, D.P. (1994) Electoral Competition with Informed and Uniformed Voters. The American Political Science Review, 88(1), pp.33-47. DOI: 10.2307/2944880

Cain, B.; Ferejohn, J. \& Fiorina, M. (1990) The Personal Vote: Constituency Service and Electoral Independence. Cambridge: Harvard University Press.

Couto, C.G. \& Arantes, R.B. (2006) Constituição, governo e democracia no Brasil. Revista Brasileira de Ciências Sociais, 21(61), pp.41-62. DOI: 10.1590/S0102-69092006000200003

Couto, C.G. \& Arantes, R.B. (2009) Uma Constituição Incomum. In: M. A. R. de Carvalho, C. Araújo e J. A. Simões (orgs) A Constituição de 1988: passado e futuro. São Paulo: Editora Hucitec.

Cox, G.W. (2005) The Efficient Secret: The Cabinet and the Development of Political Parties in Victorian England. Cambridge, Cambridge University Press.

Cox, G.W. \& Mccubbins, M.D. (2007) Legislative Leviathan: Party Government in the House. $2^{\mathrm{a}}$ Edition. Cambridge; New York: Cambridge University Press.

Crisp, B.F. \& Desposato, S.W. (2004) Constituency Building in Multimember Districts: Collusion or Conflict? Journal of Politics, 66(1), pp.136-156. DOI: 10.1046/j.1468-2508.2004.00145.x

Crisp, B. \& Ingall, R.E. (2002) Institutional Engineering and the Nature of Representation: Mapping the Effects of Electoral Reform in Colombia. American Journal of Political Science, 46(4), pp.733-748. DOI: 10.2307/3088430

Dever Jr. P. (2008) Reforming Subsidies in the Federal Budget. Politics \& Policy, 36(5), pp.854-878. DOI : 10.1111/j.1747-1346.2008.00138.x

Döring, H. (2001) Parliamentary Agenda Control and Legislative Outcomes in Western Europe. Legislative Studies Quarterly, 26(1), pp.145-165. DOI: 10.2307/440407

Downs, A. (1957) An Economic Theory of Democracy. New York, Harper and Row.

Figueiredo, A. C. \& Limongi, F. (2002) Incentivos Eleitorais, Partidos e Política Orçamentária. Dados, 45(2), pp.303-344. DOI: $10.1590 / \mathrm{S} 0011-52582002000200005$

Figueiredo, A. \& Limongi, F. (1999) Executivo e Legislativo na Nova Ordem Constitucional. Rio de Janeiro: Fundação Getúlio Vargas.

Figueiredo, A. \& Limongi, F. (2010) Poder de Agenda e Políticas Substantivas. In: M. Inacio \& L. Rennó (orgs) Legislativo Brasileiro em Perspectiva Comparada. Belo Horizonte: Editora UFMG.

Fiorina, P.M.P. (1989) Congress: Keystone of the Washington Establishment. Revised Edition. $2^{\text {a }}$ Edition. New Haven: Yale University Press.

Freitas, R. (2010) Poder de agenda e participação legislativa no presidencialismo de coalizão brasileiro. Dissertação de Mestrado. São Paulo: Universidade de São Paulo.

Graetz, M.J. (2007) Tax Reform Unraveling. Journal of Economic Perspectives, 21(1), pp.69-90. DOI: 10.1257/jep.21.1.69

Hallerberg, M. \& Von Hagen, J. (1997) Electoral Institutions, Cabinet Negotiations and Budget Deficits in the European Union. NBER Working Paper Series. [online] Cambridge: National Bureau of Economic Research, pp 3-39. Disponível em: $<$ http://www.nber.org/papers/w6341>. Acesso em: 5 de ago. 2020. DOI: 10.3386/w6341

Krehbiel, K. (1992) Information and Legislative Organization. Ann Arbor : University of Michigan Press.

Lemos, L.B. de S. (2001) O Congresso Brasileiro e a distribuição de benefícios sociais no período 1988-1994: uma análise distributivista. Dados, 44(3), pp.561-630. DOI: 10.1590/S0011-52582001000300004

Lemos, L.B. de S. \& Ricci, P. (2011) Individualismo e partidarismo na lógica parlamentar: o antes e o depois das eleições. In: T.J. Power, \& C. Zucco (orgs) O Congresso por ele mesmo: autopercepções da classe política brasileira. Belo Horizonte: Editora UFMG, pp.207-238.

Limongi, F. \& Figueiredo, A. (1998) Bases institucionais do presidencialismo de coalizão. Lua Nova, (s/v)44, pp.81-106. DOI: 10.1590/S0102-64451998000200005

Limongi, F. \& Figueiredo, A. (2005) Processo orçamentário e comportamento Legislativo: emendas individuais, apoio ao Executivo e programas de governo. Dados, 48(4), p.737-776. DOI: 10.1590/S0011-52582005000400002

Lohmann, S. (2003) Representative Government and Special Interest Politics: (We Have Met the Enemy and He is Us). Journal of Theoretical Politics, 15(3), pp.299-319. DOI: 10.1177/0951692803015003004

Maciel, M. S. (2010) Política de Incentivos Fiscais: quem recebe isenção por setores e regiões do país. Consultoria Legislativa [online] Brasília: Câmara dos Deputados, pp. 3-24. Disponível em: $<$ https://www2.camara.leg.br/atividade-legislativa/estudos-e-notas-tecnicas/publicacoes-da-consultoria-legislativa/area s-da-conle/tema20/2009_9801.pdf>. Acesso em: 5 de ago. 2020.

Mainwaring, S. (1991) Políticos, Partidos e Sistemas Eleitorais. Novos Estudos Cebrap, (s/v)29, pp.34-58.

Mainwaring, S. (1999) Rethinking Party Systems in the Third Wave of Democratization: The Case of Brazil. Stanford: Stanford University Press.

Mancuso, W.P.; Gonçalves, M.P. \& Mencarini, F. (2010) Colcha de retalhos: a política de concessão de benefícios tributários ao empresariado no Brasil (1988-2006). In: W.P. Mancuso; A.M. Leopoldi \& W. Iglecias (orgs) Estado, Empresariado e Desenvolvimento no Brasil: Novas Trajetórias. São Paulo: Editora de Cultura. pp.213-238.

Mancuso, W.P. \& Moreira, D.C. (2013) Benefícios Tributários Valem a Pena? Um Estudo de Formulação de Políticas Públicas. Revista de Sociologia e Política, 21(45), pp.107-121. DOI: 10.1590/S0104-44782013000100009

Manin, B. (1997) The Principles of Representative Government. Cambridge: Cambridge University Press.

Martins, S.P. (2009) Direito da Seguridade Social. São Paulo: Editora Atlas.

Mayhew, D.R. (1974) Congress: The Electoral Connection. New Haven: Yale University Press. 
McCombs, M. (2004) Setting the Agenda: The Mass Media and Public Opinion. Cambridge, UK; Malden, MA, USA: Polity Press.

Moisés, J.A. (2011) O desempenho do Congresso Nacional no Presidencialismo de Coalizão (1995-2006). In: J. A. Moisés (org) O papel do Congresso Nacional no Presidencialismo de Coalizão. Rio de Janeiro: Konrad-Adenauer-Stiftung.

Moreira, D.C. (2011) Benefícios Tributários Federais e Conexão Eleitoral: a concessão de benefícios referentes ao PIS, à COFINS e à CSLL. Dissertação de Mestrado. São Paulo: Universidade de São Paulo.

Olson, M. (1971) The Logic of Collective Action: Public Goods and the Theory of Groups. Cambridge, Harvard University Press.

Pereira, C. \& Mueller, B. (2002) Comportamento Estratégico em Presidencialismode Coalizão: As Relações entre Executivo e Legislativo na Elaboração do Orçamento Brasileiro. Dados, 45(2), pp.265-301. DOI: 10.1590/S0011-52582002000200004

Pereira, C. \& Mueller, B. (2003) Partidos fracos na arena eleitoral e partidos fortes na arena legislativa: a conexão eleitoral no Brasil. Dados, 46(4), pp.735-771. DOI: 10.1590/S0011-52582003000400004

Potters, J. \& Sloof, R. (1996) Interest groups: A survey of empirical models that try to assess their influence. European Journal of Political Economy, 12(3), pp.403-442. DOI: 10.1016/S0176-2680(96)00008-0

Przeworski, A.; Stokes, S.C. \& Manin, B. (eds) (1999). Democracy, Accountability, and Representation. Cambridge, U.K.; New York: Cambridge University Press.

Ricci, P. (2003a). A Medida das Leis: Do uso de Noções Genéricas à Mensuração do Imponderável. BIB: Boletim Bibliográfico de Ciências Sociais, (s/v)54, pp.101-123.

Ricci, P. (2003b) O conteúdo da produção legislativa brasileira: leis nacionais ou políticas paroquiais? Dados, 46(4), pp.699-734. DOI: 10.1590/S0011-52582003000400003

Ricci, P. (2006) De onde vem nossas leis? Origem e conteúdo da legislação em perspectiva comparada. Tese de Doutorado. São Paulo: Universidade de São Paulo.

Ricci, P. (2010) The Content of Law: Concepts and Measures in Legislative Studies. Working Paper Series 43, (Political Concepts) [online] Ciudad del Mexico: Committee on Concepts and Methods, pp. 1-27. Disponível em: <http://www.concepts-methods.org/WorkingPapers/PDF/1071>. Acesso em: 25 de set. 2020.

Shepsle, K.A. \& Weingast, B.R. (1984) Uncovered Sets and Sophisticated Voting Outcomes with Implications for Agenda Institutions. American Journal of Political Science, 28(1), pp.49-74. DOI: 10.2307/2110787

Smith, R. A. (1995) Interest Group Influence in the U. S. Congress. Legislative Studies Quarterly, 20(1), pp.89-139. DOI: $10.2307 / 440151$

Von Hagen, J.; Hallett, A. \& Strauch, R. (2001) Budgetary Consolidation in EMU. European Economy. Economic Papers 148 [online] Brussels: European Comission (Economic and Financial Affairs), pp. 5-139. Disponível em: $<$ https://ec.europa.eu/economy_finance/publications/pages/publication_summary11058_en.htm>. Acesso em: 25 de set. de 2020.

Wilson, J.Q. (1995) Political Organizations. New Jersey : Princeton University Press.

Parliamentarians in Coalition Presidentialism: decision-making power in the tax benefits policy

ABSTRACT Introduction: This article analyzes tax benefits policy during the Fernando Henrique Cardoso (1995-2002) and Luiz Inácio Lula da Silva (2003- 2010) governments. Considering that there are strong incentives for politicians to approve this kind of policy, we ask ourselves: given the division of power characteristic of the Brazilian Coalition Presidentialism system, where does the decision-making power regarding this policy lie? Materials and Methods: The legal provisions that grant and limit access to tax benefits related to PIS, COFINS and CSLL were adopted as the main unit of analyses of the legislative content. Their accounting was used to identify where the legal content subsequently approved was produced. Results: The formulation of the policy for granting tax benefits related to PIS, COFINS and CSLL is subject to the agenda of the governing coalition, which cancels the individual wishes of parliamentarians through the strategic use of the rules of the decision-making process. Furthermore, the suppression of the individual influence of parliamentarians does not cancel their participation in the formulation of this public policy. Through party leaders, the legislature acts purposefully on its content and, not infrequently, overcomes the executive power in its creation. Discussion: There are two main contributions to the literature on the topic. First, the analysis of the formulation of public policy brings to light the purposeful and assiduous participation of the Legislative Power in the approved content. It is precisely in the window of opportunity opened by the legislative dominance of the federal Executive branch that Brazilian parliamentarians have the opportunity to collaborate in the elaboration of the content of public policies. Second, the empirical conclusions leave aside the hypothesis that the formulation of the tax benefits policy is a foundation of the possible quid pro quo that exists between politicians and interest groups. If the analysis can point to a pattern of how the relationship between the State and interest groups in Brazil materializes, instead of being individually carried out, the research indicates that this relationship is built partisanly. Therefore, if there is any kind of electoral connection or quid pro quo, our bet is that it should be thought of in partisan terms and not in strictly personal ones.

KEYWORDS: legislative studies; tax benefits; public policies; Executive-Legislative relations; content analysis. 
This is an Open Access article distributed under the terms of the Creative Commons Attribution Non-Commercial License which permits unrestricted non-commercial use, distribution, and reproduction in any medium provided the original work is properly cited.

A produção desse manuscrito foi viabilizada através do patrocínio fornecido pelo Centro Universitário Internacional Uninter à Revista de Sociologia e Política. 